\title{
Role of Parafacial Nuclei in Control of Breathing in Adult Rats
}

\author{
Robert T.R. Huckstepp, Kathryn P. Cardoza, Lauren E. Henderson, and ${ }^{-}$Jack L. Feldman \\ Department of Neurobiology, David Geffen School of Medicine, University of California, Los Angles, Los Angeles, California 90095-1763
}

Contiguous brain regions associated with a given behavior are increasingly being divided into subregions associated with distinct aspects of that behavior. Using recently developed neuronal hyperpolarizing technologies, we functionally dissect the parafacial region in the medulla, which contains key elements of the central pattern generator for breathing that are important in central $\mathrm{CO}_{2}$-chemoreception and for gating active expiration. By transfecting different populations of neighboring neurons with allatostatin or $\mathrm{HM}_{4} \mathrm{D} \mathrm{G}_{\mathrm{i} / \mathrm{o}^{-} \text {-coupled }}$ receptors, we analyzed the effect of their hyperpolarization on respiration in spontaneously breathing vagotomized urethaneanesthetized rats. We identify two functionally separate parafacial nuclei: ventral $\left(\mathrm{pF}_{\mathrm{V}}\right)$ and lateral $\left(\mathrm{pF}_{\mathrm{L}}\right)$. Disinhibition of the $\mathrm{pF}_{\mathrm{L}}$ with bicuculline and strychnine led to active expiration. Hyperpolarizing $\mathrm{pF}_{\mathrm{L}}$ neurons had no effect on breathing at rest, or changes in inspiratory activity induced by hypoxia and hypercapnia; however, hyperpolarizing $\mathrm{pF}_{\mathrm{L}}$ neurons attenuated active expiration when it was induced by hypercapnia, hypoxia, or disinhibition of the $\mathrm{pF}_{\mathrm{L}}$. In contrast, hyperpolarizing $\mathrm{pF}_{\mathrm{V}}$ neurons affected breathing at rest by decreasing inspiratory-related activity, attenuating the hypoxia- and hypercapnia-induced increase in inspiratory activity, and when present, reducing expiratory-related abdominal activity. Together with previous observations, we conclude that the $\mathrm{pF}_{\mathrm{V}}$ provides a generic excitatory drive to breathe, even at rest, whereas the $\mathrm{pF}_{\mathrm{L}}$ is a conditional oscillator quiet at rest that, when activated, e.g., during exercise, drives active expiration.

Key words: active expiration; control of breathing; expiratory oscillator; parafacial respiratory group; respiration; retrotrapezoid nucleus

\section{Introduction}

Understanding how neurons are organized in microcircuits and networks is essential for comprehending behavior (Luo et al., 2008; Yuste, 2008). Here we exploit two related techniques for hyperpolarizing neurons to independently depress activity in neighboring populations of neurons and determined their role within the central pattern generator for breathing.

We hypothesize that breathing in mammals results from interactions between two oscillators (Mellen et al., 2003; Janczewski and Feldman, 2006; Feldman et al., 2013): the preBötzinger Complex (preBötC) is the kernel for inspiration (Smith et al., 1991; Tan et al., 2008), while the retrotrapezoid nucleus/parafacial respiratory group (RTN/pFRG), in whole or part, is vital for active expiration (Pagliardini et al., 2011) and $\mathrm{CO}_{2}$-chemoreception (Smith et al., 1989; Li et al., 1999; Mulkey et al., 2004).

The RTN and pFRG are parafacial regions proximal to the ventral medullary surface that project to the ventral respiratory column (Smith et al., 1989; Ellenberger and Feldman, 1990; Pagliardini et al., 2011). One notable difference between them is that in newborn rodents pFRG but not RTN neurons are respi-

Received July 18, 2014; revised Nov. 6, 2014; accepted Nov. 8, 2014.

Author contributions: R.T.R.H. and J.L.F. designed research; R.T.R.H., K.P.C., and L.E.H. performed research; R.T.R.H. analyzed data; R.T.R.H. and J.L.F. wrote the paper.

This work was supported the National Institutes of Health.

The authors declare no competing financial interests.

Correspondence should be addressed to Jack L. Feldman, Box 951763, Department of Neurobiology, David Geffen

School of Medicine, UCLA, Los Angeles, California 90095-1763. E-mail: feldman@ucla.edu.

DOI:10.1523/JNEUROSCI.2953-14.2015

Copyright $\odot 2015$ the authors $\quad 0270-6474 / 15 / 351052-16 \$ 15.00 / 0$ ratory rhythmic (Onimaru and Homma, 2003); this activity begins to wane during the early neonatal period (Oku et al., 2007) and late expiratory activity is completely absent in both regions in adult rodents at rest (Pagliardini et al., 2011).

The discovery of a putative conditional RTN/pFRG oscillator driving active expiration (Mellen et al., 2003; Janczewski and Feldman, 2006) raised the question whether parafacial neurons responsible for chemoreception and active expiration are identical, overlap, or separate. That disinhibition or activation of mostly lateral parafacial neurons elicits active expiration (Pagliardini et al., 2011) led us to hypothesize that the pFRG and RTN are separable in adult rats.

Given that the respective anatomical parafacial boundaries and distinctive functional contributions of the RTN and pFRG are poorly defined, we use unbiased descriptors based on position relative to the facial motor nucleus. Thus we refer to lateral and ventral parafacial regions, i.e., $\mathrm{pF}_{\mathrm{L}}$ and $\mathrm{pF}_{\mathrm{V}}$. We virally transfected $\mathrm{pF}_{\mathrm{L}}$ and/or $\mathrm{pF}_{\mathrm{V}}$ neurons to express distinctly different exogenous receptors, either the allatostatin receptor (AlstR; Birgül et al., 1999; Callaway, 2005) or the $\mathrm{HM}_{4} \mathrm{D}$ receptor $\left(\mathrm{HM}_{4} \mathrm{DR}\right.$; Nawaratne et al., 2008; Pei et al., 2008). Once these receptors are activated, transfected neurons are sufficiently hyperpolarized to become quiescent (Callaway, 2005; Tan et al., 2006, 2008; Nawaratne et al., 2008; Ray et al., 2011).

At rest when expiration is passive (Sherrey et al., 1988; Iizuka and Fregosi, 2007; Marina et al., 2010; Pagliardini et al., 2011), hyperpolarizing $\mathrm{pF}_{\mathrm{L}}$ neurons had no effect on breathing patterns; during hypoxia or hypercapnia, which induce active expiration, 


\section{Table 1. Table of abbreviations}

\begin{tabular}{|c|c|}
\hline Abbreviation & Definition \\
\hline $\mathrm{pF}_{\mathrm{y}}$ & Ventral parafacial region \\
\hline $\mathrm{pF}_{\mathrm{L}}$ & Lateral parafacial region \\
\hline preBötC & PreBötzinger Complex \\
\hline RTN & Retrotrapezoid nucleus \\
\hline pFRG & Parafacial respiratory group \\
\hline AlstR & Allatostatin receptor \\
\hline Alst & Allatostatin \\
\hline $\mathrm{HM}_{4} \mathrm{DR}$ & $\mathrm{HM}_{4} \mathrm{D}$ DREADD receptor \\
\hline $\mathrm{pF}_{\mathrm{L}}: \mathrm{HM}_{4} \mathrm{DR}$ & Lateral parafacial neurons transfected with $\mathrm{HM}_{4} \mathrm{D}$ DREADD receptor \\
\hline $\mathrm{pF} \mathrm{F}_{\mathrm{V}}:$ AlstR & Ventral parafacial neurons transfected with allatostatin receptor \\
\hline $\mathrm{pF}_{\mathrm{V}}: \mathrm{HM}_{4} \mathrm{DR}$ & Ventral parafacial neurons transfected with $\mathrm{HM}_{4} \mathrm{D}$ DREADD receptor \\
\hline$B+S$ & Bicuculline/strychnine \\
\hline$B+S_{p F L}$ & Bicuculline/strychnine in the $\mathrm{pF}_{\mathrm{L}}$ \\
\hline CNO & Clozapine- $N$-oxide \\
\hline $\mathrm{T}_{1}$ & Inspiratory duration \\
\hline $\mathrm{T}_{\mathrm{E}}$ & Expiratory duration \\
\hline$V_{T}$ & Tidal volume \\
\hline $\mathrm{Dia}_{\mathrm{EMG}}$ & Diaphragmatic electromyogram \\
\hline $\mathrm{GG}_{\mathrm{EMG}}$ & Genioglossal electromyogram \\
\hline $\operatorname{Abd}_{\mathrm{EMG}}$ & Abdominal electromyogram \\
\hline$f$ & Respiratory frequency \\
\hline
\end{tabular}

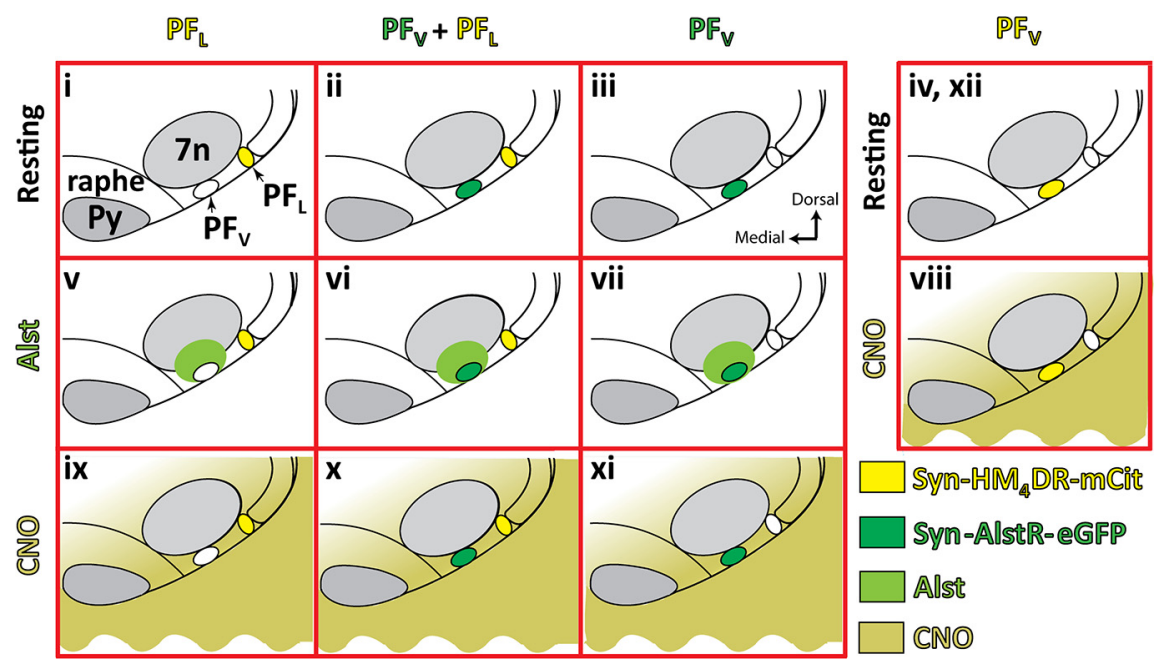

Figure 1. Overall experimental design. Rats were transfected with: syn- $\mathrm{HM}_{4} \mathrm{DR}-\mathrm{mCit}$ (light yellow) in ventral parafacial region $\left(\mathrm{pF}_{\mathrm{V}}: \mathrm{HM} \mathrm{M}_{4} \mathrm{DR}\right)$ or into lateral parafacial region $\left(\mathrm{pF}_{\mathrm{L}}: \mathrm{HM}_{4} \mathrm{DR}\right)$, or synapsin-AlstR-GFP (dark green) into $\mathrm{pF}_{\mathrm{V}}\left(\mathrm{pF}_{\mathrm{V}}:\right.$ AlstR), or both $\mathrm{pF}_{\mathrm{L}}: \mathrm{HM}_{4} \mathrm{DR}$ and $\mathrm{pF} \mathrm{F}_{\mathrm{V}}$ AlstR. All rats were subject to the same triad of experimental challenges, i.e., hypoxia, hypercapnia, and disinhibition of $\mathrm{pF}_{\mathrm{L}}$. For rats transfected with $\mathrm{pF}_{\mathrm{L}}: \mathrm{HM}_{4} \mathrm{DR}$, $\mathrm{pF}_{\mathrm{V}}:$ AlstR, or $\mathrm{pF}_{\mathrm{L}}: \mathrm{HM}_{4} \mathrm{DR}$ and $\mathrm{pF}$ : AlstR, these challenges were performed under control conditions ( $\boldsymbol{i}$-iii), following injections of Alst (light green) into $\mathrm{pF}_{\mathrm{v}}(\boldsymbol{v}$-vii), and following application of CNO (dark yellow) to medullary surface (ix- $\mathbf{x i})$. Rats transfected with $\mathrm{pF}_{\mathrm{v}}: \mathrm{HM}_{4} \mathrm{DR}$ underwent the same triad of experimental challenges, i.e., hypoxia, hypercapnia, and disinhibition of $\mathrm{pF}_{\mathrm{L}}$. These challenges were performed under control conditions (iv, before CNO; $x i i$, after (NO), and following application of $\mathrm{CNO}$ to medullary surface (viii). Data for different conditions were compared. Since Alst did not affect $\mathrm{HM}_{4}$ DR-transfected neurons and since $\mathrm{CNO}$ did not affect AlstR-transfected neurons, data for similar conditions were combined for analysis and comparisons. Thus we compared $\boldsymbol{i}+\boldsymbol{i}$ versus $\boldsymbol{i} \boldsymbol{x}+\boldsymbol{x}, \boldsymbol{i i} i$ versus $\boldsymbol{x i}, \boldsymbol{i i}+\boldsymbol{i i i}$ versus $\boldsymbol{v i}+\boldsymbol{v i}, \boldsymbol{i}$ versus $\boldsymbol{v}$, and $\boldsymbol{i v}$ + xii versus viii.

hyperpolarizing $\mathrm{pF}_{\mathrm{L}}$ neurons only attenuated expiratory activity; and disinhibition of the $\mathrm{pF}_{\mathrm{L}}$ induced active expiration, and decreased frequency $(f)$, which led to a concomitant increase in tidal volume $\left(\mathrm{V}_{\mathrm{T}}\right)$, similar to photoactivation of $\mathrm{pF}_{\mathrm{L}}$ neurons (Pagliardini et al., 2011). These effects are consistent with the $\mathrm{pF}_{\mathrm{L}}$ acting as a conditional expiratory oscillator. Distinctly different responses were seen following hyperpolarizing $\mathrm{pF}_{\mathrm{V}}$ neurons. At rest hyperpolarizing $\mathrm{pF}_{\mathrm{V}}$ neurons decreased diaphragmatic EMG ( Dia $_{\mathrm{EMG}}$ ) amplitude, and reduced $\mathrm{V}_{\mathrm{T}}$ with no change in $f$; during hypoxia or hypercapnia, hyperpolarizing $\mathrm{pF}_{\mathrm{V}}$ neurons attenuated in- creases in inspiratory-related genioglossal and expiratory-related abdominal $\mathrm{EMG}$ amplitudes ( $\mathrm{GG}_{\mathrm{EMG}}$ and $\mathrm{Abd}_{\mathrm{EMG}}$, respectively), with no change in $f$ or $\mathrm{V}_{\mathrm{T}}$; and following disinhibition of $\mathrm{pF}_{\mathrm{L}}$ neurons, hyperpolarizing $\mathrm{pF}_{\mathrm{V}}$ neurons reduced expiratoryeled $\operatorname{Abd}_{\mathrm{EMG}}$, but did not affect the reduction in $f$ or concomant increase in $\mathrm{V}_{\mathrm{T}}$. Thus the $\mathrm{pF}_{\mathrm{V}}$ appears to affect both appear to affect respiratory frequency. We conclude that the $\mathrm{pF}_{\mathrm{I}}$ and $\mathrm{pF}_{\mathrm{V}}$ are functionally distinct, with the $\mathrm{pF}_{\mathrm{V}}$ providing an excitatory drive to breathe, even at rest, whereas the $\mathrm{pF}_{\mathrm{L}}$ is a condiactive expiration.

\section{Materials and Methods}

Viral design and handling. Two different viruses were used: AAV-2/5 hSyn$\mathrm{HA}-\mathrm{hM}_{4} \mathrm{D}(\mathrm{Gi})$-IRES-mCitrine $\left(\mathrm{HM}_{4} \mathrm{DR}\right.$; University of North Carolina Gene Therapy Vector Core, Chapel Hill, NC) at a titer of $8 \times 10^{12} \mathrm{vp} / \mathrm{ml}$, and; AAV-DJ synapsin-allatostatin receptor-GFP (AlstR). We designed the latter virus using Nucleotide/Blast (NCBI, Bethesda, MD), University Santa Cruz Genome Browser (UCSC, Santa Cruz, CA), Cister (Boston University, Boston, MA), and BioEdit (Ibis Biosciences). The insert (synapsin-SV40 SD/SA-AlstR) was synthesized (GenScript), and placed into the VPK 418 pAAV-IRES-GFP plasmid vector (Cell Biolabs), modified so that it lacked the CMV promoter and $\beta$-globin intron. The plasmid was then used to create a custom AAV-DJ virus (Salk Institute, $\mathrm{GT}^{3}$ Core) at a titer of $5.8 \times 10^{13} \mathrm{vp} / \mathrm{ml}$. The viruses were aliquoted and stored at $-80^{\circ} \mathrm{C}$. On the day of injection, aliquots containing viruses were removed and held at $4^{\circ} \mathrm{C}$, viruses were loaded by capillary action into glass pipettes, and pipettes containing viruses were placed into an electrode holder for pressure injection.

Viral transfection of $p F_{V}$ and $p F_{L}$. All protocols were approved by the University of California Los Angeles Chancellor's Animal Research Committee. Male Sprague Dawley rats $(350-450 \mathrm{~g})$ were anesthetized by intraperitoneal injection of ketamine $(100 \mathrm{mg} / \mathrm{kg}$; Clipper Distribution), xylazine (10 mg/kg; Lloyd), and atropine (1 mg/kg; Westward Pharmaceutical); anesthesia was maintained with isoflurane (0.5-2\%; Piramal Healthcare) throughout the procedure as required. Rats were placed in a prone position in a stereotaxic apparatus (Kopf Instruments) on a heating pad (TCAT 2-LV; Physitemp) and body temperature was maintained at a minimum of $36.5^{\circ} \mathrm{C}$ via a thermocouple. The head was leveled and glass pipettes were placed stereotaxically into the $\mathrm{pF}_{\mathrm{V}}$ or $\mathrm{pF}_{\mathrm{L}}$ (Figs. 1,2). The $\mathrm{pF}_{\mathrm{V}}$ was defined as the area ventral to the caudal half of the facial nucleus, between the pyramidal tract and the spinal trigeminal tract (coordinates: $1.8 \mathrm{~mm}$ lateral and $11.4 \mathrm{~mm}$ caudal from bregma, and $9.4 \mathrm{~mm}$ ventral from the surface of the cerebellum; Fig. $2 A i)$. The $\mathrm{pF}_{\mathrm{L}}$ was defined as the area ventral to the lateral edge of the facial nucleus, juxtaposed to the spinal trigeminal tract (coordinates: $2.5 \mathrm{~mm}$ lateral and $11.1 \mathrm{~mm}$ caudal from bregma, and $9.2 \mathrm{~mm}$ ventral from the surface of the cerebellum; Fig. 2Ai). The virus solutions were pressure injected (100-150 nl) bilaterally using a Picospritzer II (General Valve) controlled by a Master 8 pulse generator (A.M.P.I.). Pipettes were left in place for 3-5 min to prevent back flow of the virus solution up the pipette track.

There were four virus injection protocols (Fig. 1): (1) $\mathrm{HM}_{4} \mathrm{DR}$ in $\mathrm{pF}_{\mathrm{L}}$ neurons $\left(\mathrm{pF}_{\mathrm{L}}: \mathrm{HM}_{4} \mathrm{DR}\right),(2)$ AlstR in $\mathrm{pF}_{\mathrm{V}}$ neurons $\left(\mathrm{pF}_{\mathrm{V}}\right.$ :AlstR), (3) Both 
$\mathrm{pF}_{\mathrm{L}}: \mathrm{HM}_{4} \mathrm{DR}$ and $\mathrm{pF}_{\mathrm{V}}: \mathrm{AlstR}\left(\mathrm{pF}_{\mathrm{L}}: \mathrm{HM}_{4} \mathrm{DR}+\right.$ $\mathrm{pF}_{\mathrm{V}}$ :AlstR), and (4) $\mathrm{HM}_{4} \mathrm{DR}$ in $\mathrm{pF}_{\mathrm{V}}$ neurons $\left(\mathrm{pF}_{\mathrm{V}}: \mathrm{HM}_{4} \mathrm{DR}\right)$.

Postoperatively, rats received buprenorphine $(0.1 \mathrm{mg} / \mathrm{kg}$; Reckitt Benckiser) intraperitoneally and meloxicam ( $2 \mathrm{mg} / \mathrm{kg}$; Norbrook) subcutaneously, followed by $10 \mathrm{~d}$ of oral antibiotics (TMS; Hi-Tech Pharmacal) and $4 \mathrm{~d}$ of oral meloxicam $(0.05 \mathrm{mg} / \mathrm{ml})$ in their drinking water. Rats were allowed 3-6 weeks for recovery and viral expression, with food and water ad libitum.

Ventral approach. Anesthesia was induced with isoflurane and maintained throughout surgery with urethane (Fig. 2Aii; 1.2-1.7 g/kg; Sigma) diluted in standard sterile saline $(0.9 \%$ $\mathrm{NaCl}$; Hospira) via a femoral catheter: urethane anesthesia was vital to seeing expiratoryrelated abdominal activity, as activity was not seen when isoflurane or ketamine were used (data not shown). Rats were placed supine onto a stereotaxic apparatus on a heating pad and core body temperature was maintained at a minimum of $36.5^{\circ} \mathrm{C}$ via a thermocouple. The trachea was cannulated. Respiratory flow was monitored via a flow head connected to a transducer (GM Instruments) and $\mathrm{CO}_{2}$ via a capnograph (Type 340; Harvard Apparatus) connected to the tracheal tube. Paired EMG wire electrodes (Cooner Wire) were inserted into the genioglossus, diaphragm, and oblique abdominal muscles to record respiratoryrelated activity. After the anterior neck muscles were removed, a basio-occipital craniotomy exposed the ventral medullary surface, and the dura was resected. After bilateral vagotomy, the exposed tissue around the neck and the mylohyoid muscle was covered with dental putty (Reprosil; Dentsply Caulk) to prevent drying. The rat was left for $30 \mathrm{~min}$ to allow baseline recordings to stabilize.

At resting levels, ventilation was continuous, consisting of alternation of active contraction of inspiratory muscles, e.g., diaphragm, and passive expiration. Active expiration was initiated by substituting various gas mixtures for room air, i.e., hypoxia $\left(8 \% \mathrm{O}_{2}\right.$ and $\left.92 \% \mathrm{~N}_{2}\right)$ or hypercapnia $\left(9 \% \mathrm{CO}_{2}, 21 \% \mathrm{O}_{2}\right.$, and $\left.70 \% \mathrm{~N}_{2}\right)$, or by disinhibition within the $\mathrm{pF}_{\mathrm{L}}$ with the $\mathrm{GABA}_{\mathrm{A}}$ antagonist, bicuculline methobromide (250 $\mu \mathrm{M}$; Tocris Bioscience) combined with the glycine antagonist strychnine hydrochloride (250 $\mu \mathrm{M}$; Sigma-Aldrich) diluted in standard sterile saline.

All experiments began by testing responses to hypoxia, hypercapnia, and $\mathrm{pF}_{\mathrm{L}}$ disinhibition [via injection of bicuculline/strychnine $(\mathrm{B}+\mathrm{S}$ ) in the $\left.\mathrm{pF}_{\mathrm{L}}\left(\mathrm{B}+\mathrm{S}_{\mathrm{pFL}}\right)\right]$ under resting conditions (Fig. $1 i-i v$ ). Rats were exposed to 1 min of hypoxia followed by a 15 min recovery period breathing room air, then changed to 2 min of hypercapnia after which rats were allowed 20 min breathing room air for baseline recordings to stabilize. Finally, rats received bilateral B + $\mathrm{S}_{\mathrm{pFL}}$ followed by a $30 \mathrm{~min}$ recovery period while breathing room air. $\mathrm{pF}_{\mathrm{L}}$ coordinates via a ventral approach were as follows: $2.5 \mathrm{~mm}$ lateral from the basilar artery, $0.9 \mathrm{~mm}$ rostral from the most rostral hypoglossal nerve rootlet, and $0.2 \mathrm{~mm}$ dorsal from the ventral surface. The B $+\mathrm{S}$ solution was pressure injected (50-100 $\mathrm{nl})$ bilat-
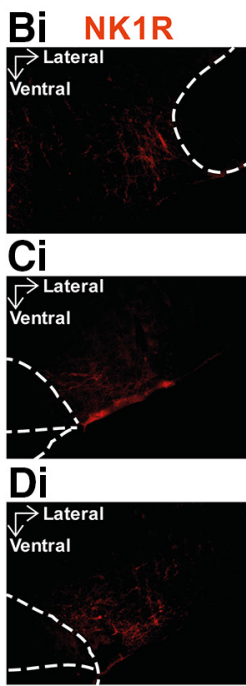

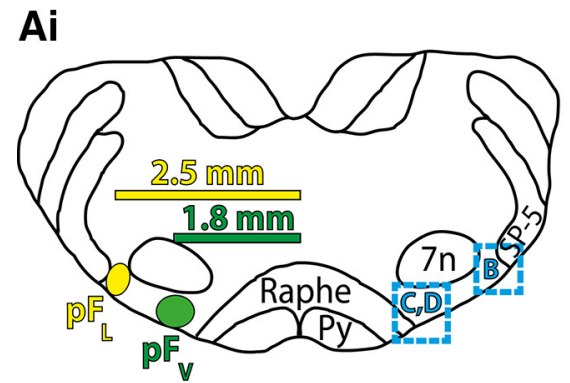

Aii
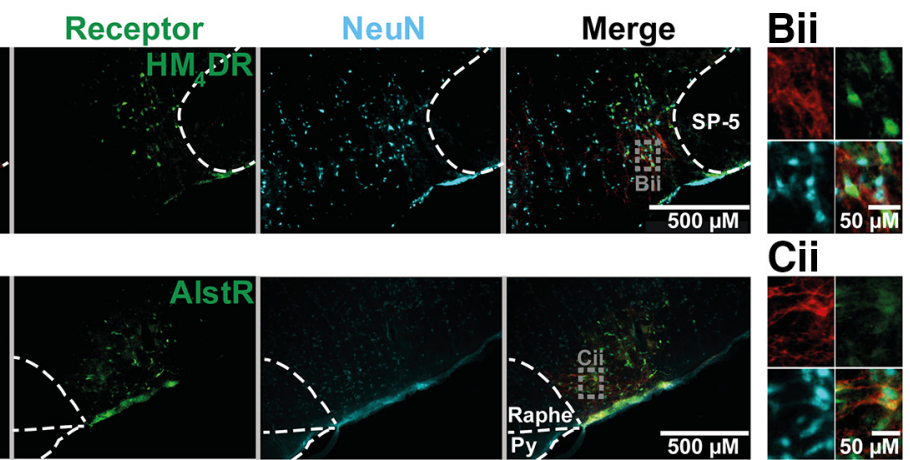

Cii
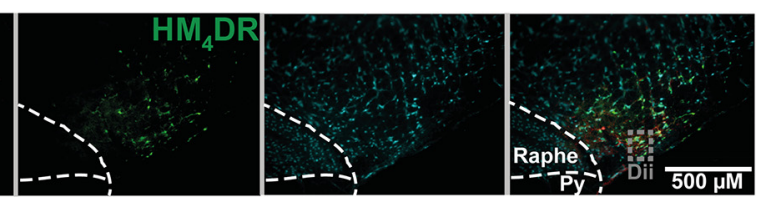

Dii

Figure 2. Neuronal transfection in parafacial regions. A, Localization of injections into $\mathrm{pF}_{\mathrm{V}}$ and $\mathrm{pF}_{\mathrm{L}}$. $\boldsymbol{A \boldsymbol { i }}$, Transverse view of medulla at bregma $-11.25 \mathrm{~mm}$. Dashed squared blue boxes identify location of sections illustrating immunocytochemistry shown in $\boldsymbol{B}-\boldsymbol{D}$. Aii, Ventral view of medullary surface. $\boldsymbol{A i}$, Aii, Green circle shows location of AlstR injection sites for $\mathrm{pF}_{\mathrm{v}}(\boldsymbol{C} \boldsymbol{C})$,yellow circle shows location of $\mathrm{HM}_{4} \mathrm{DR}$ injection sites for $\mathrm{pF}_{\mathrm{L}}(\boldsymbol{B i})$ and $\mathrm{pF}_{\mathrm{V}}(\boldsymbol{D i})$. Bi-Di, Micrographs of injection sites: neurons (blue) transfected with AlstR (in Ci) expressing GFP, or $\mathrm{HM}_{4} \mathrm{DR}$ (in Bi, Di) expressing mCitrine, colocalized with NK1R (red). Bii-Dii, Expanded micrographs from merged figures in $\boldsymbol{B i}-\mathbf{D i}$ (dashed gray boxes): NeuN (blue), GFP, or mCitrine (green), and NK1R (red). Py, pyramidal tract; SP-5, spinal trigeminal tract; $7 \mathrm{n}$, facial nucleus.

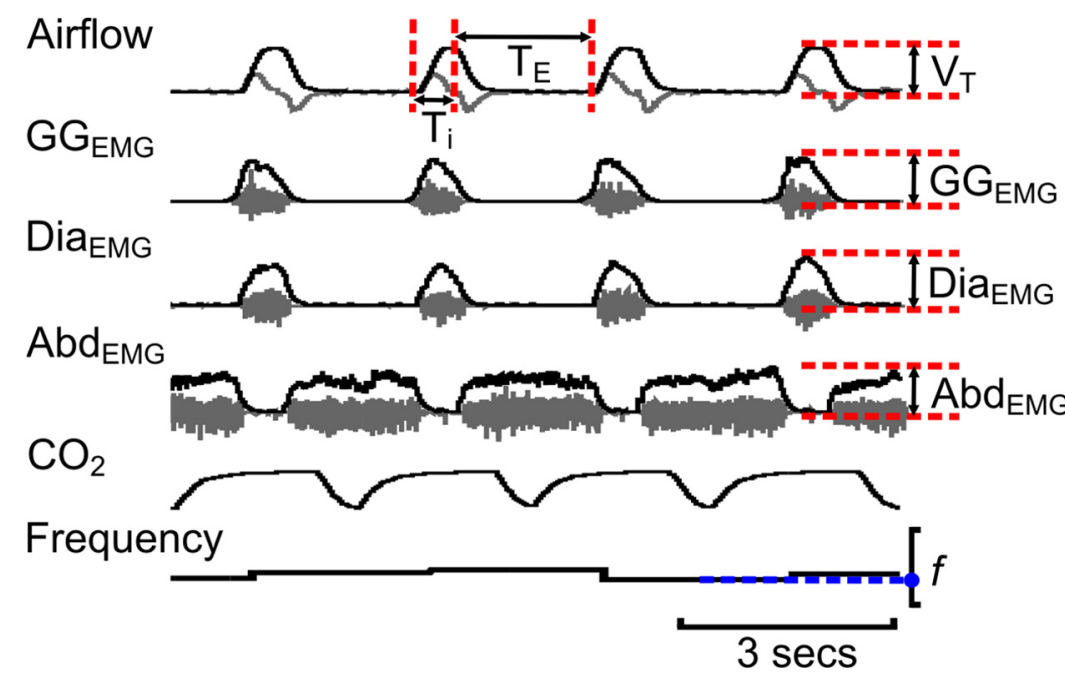

Figure 3. Measurement of respiratory variables. Gray traces are raw data (not shown in Figs. 4-13). Black traces are integrated data, end-tidal $\mathrm{CO}_{2}$, and frequency (shown in Figs. 4-13). Maximum and minimum values for each variable were measured from integrated traces (red dashed lines) and the differences, along with frequency (blue line + dots), were used to calculatef, $\mathrm{T}_{1}, \mathrm{~T}_{\mathrm{E}}, \mathrm{V}_{\mathrm{T}_{\mathrm{T}}}, \mathrm{GG}_{\mathrm{EMG}}, \mathrm{Dia}_{\mathrm{EMG}}$, and $\mathrm{Abd}_{\mathrm{EMG}}$

erally using a Picospritzer II controlled by a Master 8 pulse generator. To avoid disruption of the tissue the $\mathrm{B}+\mathrm{S}$ solution was injected at $\sim 60 \mathrm{nl} / \mathrm{min}$.

After experiments were performed under resting conditions, rats transfected with $\mathrm{pF}_{\mathrm{V}}: \mathrm{AlstR}$ or $\mathrm{pF}_{\mathrm{L}}: \mathrm{HM}_{4} \mathrm{DR}+\mathrm{pF}_{\mathrm{V}}$ :AlstR were given a 


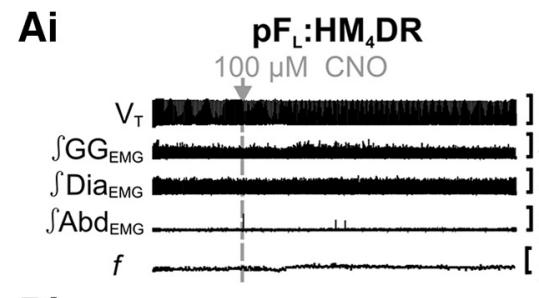

$\mathrm{Bi}$

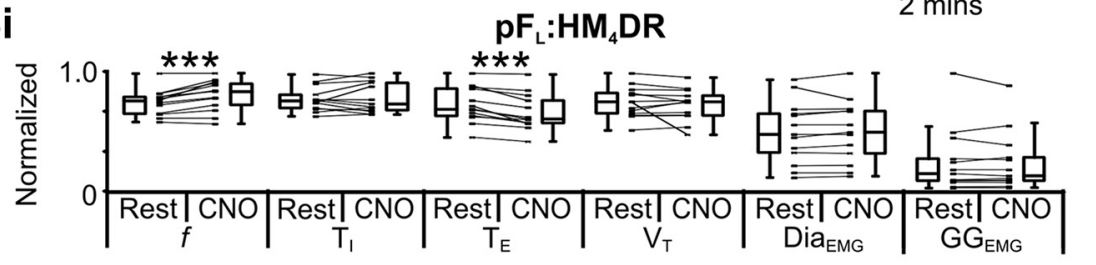

Bii

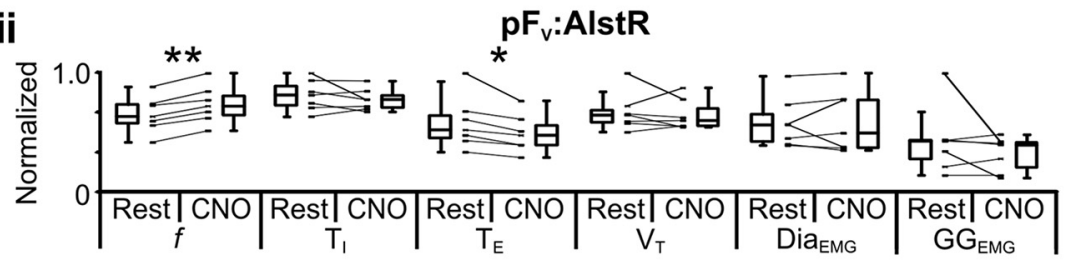

C

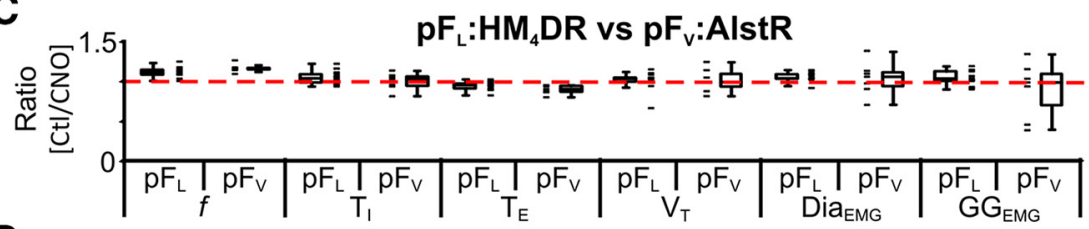

D

\begin{tabular}{|c|c|c|c|c|c|c|}
\hline $\begin{array}{l}\text { Values: } \\
\text { median, IQR } \\
\end{array}$ & $f($ breath $/ \mathrm{min})$ & $T_{1}$ (secs) & $T_{E}($ secs $)$ & $V_{T}(m L)$ & $\mathrm{Dia}_{\mathrm{EMG}}$ & $\mathbf{G G}_{\mathrm{EMG}}$ \\
\hline Rest $\left(p F_{L}\right)$ & $49.9,9.2$ & $0.3,0.1$ & $0.9,0.3$ & $3.9,0.9$ & $16.6,11.3$ & $6.9,8.3$ \\
\hline CNO $\left(p F_{L}\right)$ & 55.0 & $0.3,0.1$ & & $3.8,0.8$ & $17.2,12.2$ & $6.1,8.9$ \\
\hline$P=$ & & 0.7 & & 0.9 & 0.1 & 0.8 \\
\hline Rest $\left(p F_{v}\right)$ & & & & & $20.0,7.9$ & $14.7,5.3$ \\
\hline $\mathrm{CNO}\left(p F_{\mathrm{V}}\right)$ & & $0.3,0.0$ & & $3.4,0.8$ & $17.6,14.0$ & $13.7,7.0$ \\
\hline$P=$ & & & & 0.7 & 0.7 & 0.5 \\
\hline Ratio $\left(p F_{L}\right)$ & & 1.0, & & 1.0, & $1.0,0.1$ & $1.0,0.1$ \\
\hline Ratio $\left(p F_{V}\right)$ & $1.1,0.0$ & $1.0,0.1$ & $0.9,0.1$ & $1.0,0.1$ & $1.0,0.2$ & $0.9,0.4$ \\
\hline$P=$ & 0.06 & 0.5 & 0.06 & 0.8 & 0.8 & 0.5 \\
\hline
\end{tabular}

Figure 4. Effect of $\mathrm{CNO}$ in rats with and without $\mathrm{HM}_{4} \mathrm{DRs}$. $A$, Integrated traces: gray arrows and vertical dashed lines indicate application of $\mathrm{CNO}_{\mathrm{O}}$ in $\mathrm{pF}_{1}: \mathrm{HM}_{4} \mathrm{DR}$ rats (Ai) or in rats lacking $\mathrm{HM}_{4}$ DRs, i.e., $\mathrm{PF}_{\mathrm{V}}$ :AlstR rats (Aii). $\boldsymbol{B}$, Comparison of respiratory variables before and after $\mathrm{CNO}_{\mathrm{N}}$ in $\mathrm{pF}_{\mathrm{L}}: \mathrm{HM}_{4} \mathrm{DR}$ rats $(\boldsymbol{B i})$ and $\mathrm{pF}$ :AlstR rats (Bii). Lines connect data from individual experiments, and boxand-whisker plots show combined data. Data in $\boldsymbol{B} \boldsymbol{i}$ and $\boldsymbol{B i i}$ are normalized to highest value for that parameter, i.e., $f, T_{1}, T_{E}, V_{T}$, $\mathrm{GG}_{\mathrm{EMG}}, \mathrm{Dia}_{\mathrm{EMG}}$, or $\mathrm{Abd}_{\mathrm{EMG}}$, regardless of whether it belonged to control or $\mathrm{CNO}$ group. C, Comparison of ratio changes between effects of $\mathrm{CNO}$ on $\mathrm{pF}_{1}: \mathrm{HM}_{4} \mathrm{DR}$ and $\mathrm{pF}_{\mathrm{v}}:$ AlstR rats. Box-and-whisker plots show combined data, with data points from individual experiments. Data in $\boldsymbol{C}$ are expressed as ratios of resting values, and red horizontal dashed line represents a ratio of 1. $\boldsymbol{D}$, Table containing median, IQR, and $p$ values, from data represented in $\boldsymbol{A} .{ }^{*} p<0.05$, ${ }^{* *} p<0.01$, ${ }^{* *} p<0.005$.

bilateral injection of Alst (10 $\mu \mathrm{M}$; Antagene) diluted in standard sterile saline into the $\mathrm{pF}_{\mathrm{V}}$ to test the effects of inactivation of the $\mathrm{pF}_{\mathrm{V}}$ (Fig. $1 v i$,vii), and rats transfected with $\mathrm{pF}_{\mathrm{L}}: \mathrm{HM}_{4} \mathrm{DR}$ were given Alst to test for nonspecific effects of Alst in rats that lack the AlstR (Fig. 1v). $\mathrm{pF}_{\mathrm{V}}$ coordinates via a ventral approach were as follows: $1.8 \mathrm{~mm}$ lateral from the basilar artery, $0.6 \mathrm{~mm}$ rostral from the most rostral hypoglossal nerve rootlet, and $0.2 \mathrm{~mm}$ dorsal from the ventral surface. At $10 \mathrm{~min}$ post Alst, the response to hypoxia was re-examined. Additional Alst, with a $5 \mathrm{~min}$ stabilization period, preceded subsequent retesting of, first, the response to hypercapnia, and second, $\mathrm{B}+\mathrm{S}_{\mathrm{pFL}}$. Then, after sufficient time for breathing to return to baseline levels $(\sim 30 \mathrm{~min})$, clozapine- $\mathrm{N}$-oxide (CNO; $100 \mu \mathrm{M}$; Santa Cruz Biotechnology) diluted in standard sterile saline was applied to the ventral medullary surface of rats transfected with $\mathrm{pF}_{\mathrm{L}}: \mathrm{HM}_{4} \mathrm{DR}+\mathrm{pF}$ : $\mathrm{AlstR}$ or $\mathrm{pF}_{\mathrm{L}}: \mathrm{HM}_{4} \mathrm{DR}$ to test the effects of $\mathrm{pF}_{\mathrm{L}}$ inactivation (Fig. 1ix, x), and CNO was applied to the ventral medullary surface of rats transfected with $\mathrm{pF}_{\mathrm{V}}$ :AlstR to test for nonspecific effects of $\mathrm{CNO}$ in rats that lack the $\mathrm{HM}_{4} \mathrm{DR}$ (Fig. 1xi); to allow breathing to stabi- lize, measurements were taken after $10 \mathrm{~min}$. Then, the rats were again tested for responses to hypoxia, hypercapnia, and $\mathrm{B}+\mathrm{S}_{\mathrm{pF}_{\mathrm{L}}}$, with $\mathrm{CNO}$ reapplied 5 min before each test.

As there was no difference in the responses to $\mathrm{pF}_{\mathrm{L}}$ inactivation in rats transfected with $\mathrm{pF}_{\mathrm{L}}: \mathrm{HM}_{4} \mathrm{DR}$ (Fig. 1ix) or $\mathrm{pF}_{\mathrm{L}}: \mathrm{HM}_{4} \mathrm{DR}+$ $\mathrm{pF}_{\mathrm{v}}$ :AlstR (Fig. $1 x$ ), the data from both groups were combined for analysis. As there was also no difference in the responses to Alst in rats transfected with $\mathrm{pF}_{\mathrm{V}}$ :AlstR (Fig. 1vii) or $\mathrm{pF}_{\mathrm{L}}$ : $\mathrm{HM}_{4} \mathrm{DR}+\mathrm{pF}_{\mathrm{V}}$ :AlstR (Fig. 1vi), the data from both groups were combined for analysis. Thus experiments represented by Figure 1, $i$ and $i$, were compared with $i x$ and $x$, iii were compared with $x i, i i+i i i$ were compared with $v i+v i i$, and $i$ were compared with $v$.

Rats transfected with $\mathrm{HM}_{4} \mathrm{DR}$ in the $\mathrm{pF}_{\mathrm{V}}$, i.e., $\mathrm{pF}_{\mathrm{V}}: \mathrm{HM}_{4} \mathrm{DR}$ rats, were only tested for their response to CNO. As for other experiments, we measured the responses under resting conditions to hypoxia and hypercapnia. Then, after sufficient time for breathing to return to baseline levels ( $\sim 30 \mathrm{~min}), \mathrm{CNO}$ was applied to the ventral medullary surface to test the effects of $\mathrm{pF}_{\mathrm{V}}$ inactivation (Fig. 1viii); to allow breathing to stabilize, measurements were taken after 10 $\min$. Then, the rats were again tested for responses to hypoxia and hypercapnia, with $\mathrm{CNO}$ reapplied $5 \mathrm{~min}$ before each test. Finally, after washing off the $\mathrm{CNO}$, the protocol was repeated a third time, again under resting conditions. The pre-experimental and postexperimental conditions were averaged for control data used for analysis (Fig. 1iv, xii).

Localization of transfected neurons. Rats were killed by an overdose of urethane and transcardially perfused using a peristaltic pump (Cole Palmer) with saline followed by cold $\left(4^{\circ} \mathrm{C}\right)$ paraformaldehyde (PFA; 4\%; Thermo Fischer Scientific). The medulla was harvested and postfixed in $4 \%$ PFA overnight at $4^{\circ} \mathrm{C}$, then cryoprotected in sucrose $(30 \%$; Thermo Fischer Scientific) in standard PBS (1-3 d at $4^{\circ} \mathrm{C}$ ). PBS contained the following (in $\mathrm{mm}$ ): $137 \mathrm{NaCl}, 2.7 \mathrm{KCl}, 10 \mathrm{Na}_{2} \mathrm{HPO}_{4}$, and 1.8 $\mathrm{KH}_{2} \mathrm{PO}_{4}$, adjusted to $\mathrm{pH} 7.4$ with $\mathrm{HCl}$ (all reagents from Thermo Fischer Scientific).

Brainstems were transversely sectioned at 40 $\mu \mathrm{m}$ with a cryostat (Leica Biosystems). Freefloating sections were incubated overnight in PBS containing $0.1 \%$ Triton X-100 (PBT) and the following primary antibodies (1:500): mouse anti-NeuN (EMD Millipore), rabbit anti-neurokinin 1 receptor (NK1R; EMD Millipore), and chicken anti- GFP (Aves Labs). The tissue was washed in PBS six times for $5 \mathrm{~min}$ per wash and then incubated separately for $2-4 \mathrm{~h}$ in a solution of PBT containing the following secondary antibodies (1:250): donkey antimouse Alexa Fluor 647, donkey anti-rabbit rhodamine red, and donkey anti-chicken Alexa Fluor 488 (Jackson ImmunoResearch). The tissue was again washed in PBS six times for $5 \mathrm{~min}$ per wash. Slices were mounted onto polylysine-coated slides, dehydrated overnight at room temperature, and coverslipped using Cytoseal 60 (Electron Microscopy Sciences) mounting medium. Slides were observed under an AxioCam 2 Zeiss fluorescent microscope with AxioVision acquisition software (Zeiss). Images were acquired and exported as TIFF files.

To calculate the transfection efficiencies of the two viruses, we counted transfected neurons from a single representative $40 \mu \mathrm{m}$ section at the core of the $\mathrm{pF}_{\mathrm{L}}: \mathrm{HM}_{4} \mathrm{DR}(n=3)$ and $\mathrm{pF}_{\mathrm{V}}$ :AlstR $(n=3)$ injection sites from different rats. Images of these sections were opened in CorelDRAW 
(Corel), and an ROI was drawn around the injection site. Then NeuN expression within the ROI was marked, using different colors, as being colocalized with a virally driven fluorophore (i.e., mCitrine or GFP) or not. The ROI containing the different colored marks was then exported as a TIFF file and cell counts were performed in ImageJ (NIH). Data were exported to Excel (Microsoft) for further analysis, and statistical analysis was performed in Igor Pro (WaveMetrics). Cell counts are expressed as mean and SD.

Data analysis and statistics. EMG signals and airflow measurements were collected using preamplifiers (P5; Grass) connected to a PowerLab AD board (ADInstruments) in a laboratory computer running LabChart software (ADInstruments), and were sampled at $400 \mathrm{~Hz}$ per channel. High-pass filtered $(>0.1 \mathrm{~Hz})$ flow head measurements were used to calculate: inspiratory duration $\left(\mathrm{T}_{\mathrm{I}}\right)$, expiratory duration $\left(\mathrm{T}_{\mathrm{E}}\right)$, and tidal volume $\left(\mathrm{V}_{\mathrm{T}}\right)$. $\mathrm{V}_{\mathrm{T}}$ was calculated as the change in amplitude of the integrated airflow signal during inspiration, converted to milliliters by comparison to calibration with a $3 \mathrm{ml}$ syringe (Fig. 3). From the integrated airflow signal, $T_{I}$ was measured from the beginning of inspiration until peak $\mathrm{V}_{\mathrm{T}}$, and $\mathrm{T}_{\mathrm{E}}$ was measured from peak $\mathrm{V}_{\mathrm{T}}$ to the beginning of the next inspiration (Fig. 3). Frequency $(f)$ was (1/ $\left(\mathrm{T}_{\mathrm{I}}+\mathrm{T}_{\mathrm{E}}\right)$; Fig. 3). EMG data were integrated $(\tau=0.05 \mathrm{~s})$, and respiratory muscle activity was calculated as the peak amplitude of the integrated $\mathrm{Dia}_{\mathrm{EMG}}, \mathrm{GG}_{\mathrm{EMG}}$, and $\mathrm{Abd}_{\mathrm{EMG}}$, respectively (Fig. 3). There were two forms of activity seen on the $\mathrm{GG}_{\mathrm{EMG}}$ trace: one phase locked with inspiration and the other phase locked with expiration. Inspiratory $\mathrm{GG}_{\mathrm{EMG}}$ activity was present under all conditions tested, and as such $\mathrm{GG}_{\mathrm{EMG}}$ measurements during the inspiratory phase of respiration are analyzed throughout this manuscript. Expiratory $\mathrm{GG}_{\mathrm{EMG}}$ activity is not present at rest, but could be initiated during active expiration. As expiratory $\mathrm{GG}_{\mathrm{EMG}}$ activity was not consistently induced by any of the above manipulations, either in the same preparation or between different preparations, these data were not included for further analysis. To obtain control values, the 20 cycles preceding each experimental manipulation for all parameters were averaged. Under hypoxic or hypercapnic conditions, measurements from the 20 cycles preceding stimulus cessation were averaged. As the time of the peak response to $\mathrm{B}+\mathrm{S}_{\mathrm{pF}_{\mathrm{L}}}$ was different on each channel (airflow, $\mathrm{Dia}_{\mathrm{EMG}}, \mathrm{GG}_{\mathrm{EMG}}$, and $\mathrm{Abd}_{\mathrm{EMG}}$ ), for values for the effect of $\mathrm{B}+$ $\mathrm{S}_{\mathrm{pFL}}, 20$ cycles were averaged at the peak of change on each channel separately; all measurements from the integrated airflow channel $\left(f, \mathrm{~V}_{\mathrm{T}}\right.$, $\mathrm{T}_{\mathrm{I}}$, and $\mathrm{T}_{\mathrm{E}}$ ) were made from the same 20 cycles. Data were analyzed off-line, and then exported to Excel for further analysis. All statistical tests were performed using Igor Pro. In one $\mathrm{pF}_{\mathrm{V}}: \mathrm{HM}_{4} \mathrm{DR}$ experiment, data were excluded from analysis from the $\mathrm{GG}_{\mathrm{EMG}}$ channel, as the baseline was unstable in the period preceding the hypercapnic challenge.

For each variable, we calculated the ratio change induced by each stimulus under each condition. We divided the average of 20 cycles at the peak of the stimulus by the average of 20 cycles preceding the stimulus. These ratios were then used for statistical comparison. For example, to compute the ratio change for the effects of hyperpolarizing $\mathrm{pF}_{\mathrm{L}}: \mathrm{HM}_{4} \mathrm{DR}$ neurons with $\mathrm{CNO}$ on respiratory changes induced by $\mathrm{B}+\mathrm{S}_{\mathrm{pF}_{\mathrm{L}}}$ (1) we computed the ratio of the change of each variable induced by $\mathrm{B}+\mathrm{S}_{\mathrm{pFL}}$ compared with its control, which we designate as $\left[\mathrm{B}+\mathrm{S}_{\mathrm{pF}_{\mathrm{L}}} / \mathrm{Ctl}\right]$; (2) we computed the ratio of the change of each variable induced by $\mathrm{B}+\mathrm{S}_{\mathrm{pF}_{\mathrm{L}}}$ in the presence of $\mathrm{CNO}$ compared with its control in the presence of $\mathrm{CNO}$, which we designate as $\left[\left(\mathrm{B}+\mathrm{S}_{\mathrm{pFL}}+\mathrm{CNO}\right) /(\mathrm{Ctl}+\mathrm{CNO})\right]$; and (3) we compared the ratio changes of both groups, i.e., $\left[\mathrm{B}+\mathrm{S}_{\mathrm{pF}_{\mathrm{L}}} / \mathrm{Ctl}\right]$ vs $[(\mathrm{B}+$ $\left.\left.\mathrm{S}_{\mathrm{pF}_{\mathrm{L}}}+\mathrm{CNO}\right) /(\mathrm{Ctl}+\mathrm{CNO})\right]$. If the ratio change in the presence of $\mathrm{CNO}$ was significantly closer to 1 , then we conclude hyperpolarizing $\mathrm{pF}_{\mathrm{L}}$ : $\mathrm{HM}_{4} \mathrm{DR}$ neurons reduced the effect of changes induced by $\mathrm{B}+\mathrm{S}_{\mathrm{pF}_{\mathrm{L}}}$. If the ratio change in the presence of $\mathrm{CNO}$ was significantly further away from 1 , then we conclude hyperpolarizing $\mathrm{pF}_{\mathrm{L}}: \mathrm{HM}_{4} \mathrm{DR}$ neurons potentiated the effect of changes induced by $\mathrm{B}+\mathrm{S}_{\mathrm{pF}_{\mathrm{L}}}$. If the ratio changes were not significantly different, then we conclude that hyperpolarizing $\mathrm{pF}_{\mathrm{L}}$ : $\mathrm{HM}_{4} \mathrm{DR}$ neurons did not modulate changes induced by $\mathrm{B}+\mathrm{S}_{\mathrm{pF}_{\mathrm{L}}}$. Ratios normalized datasets, which removed large differences in absolute values between datasets and led to fewer statistical outliers.

As described above, for each rat we calculated the average of 20 cycles preceding the stimulus $\left(\bar{X}_{\text {control }}\right)$, and the average of 20 cycles during the stimulus $\left(\bar{X}_{\text {stimulus }}\right)$. Both groups, the $\bar{X}_{\text {control }}$ values and their associated 


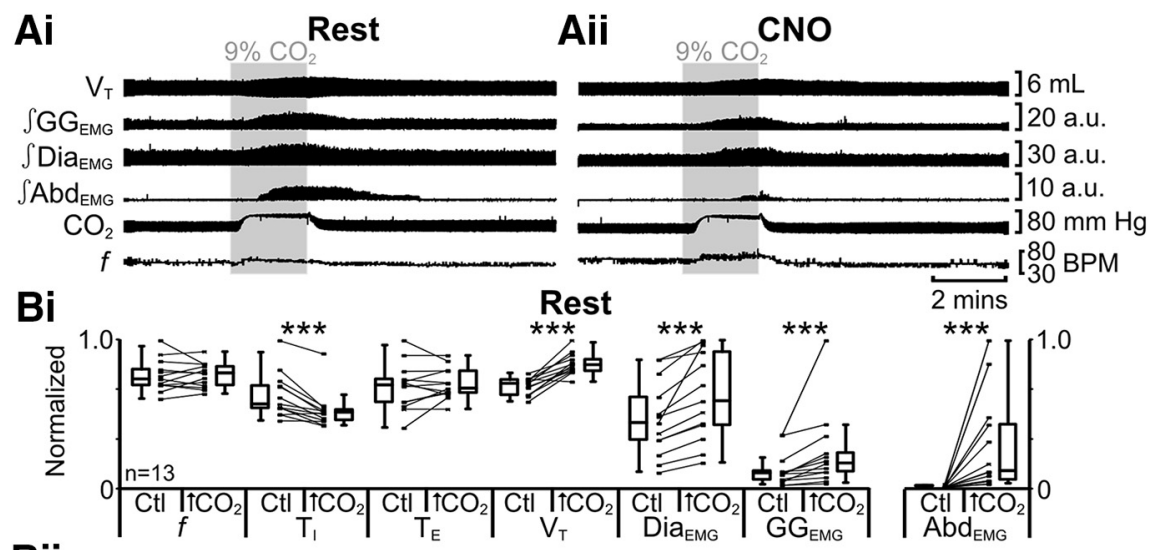

$\mathrm{Bii}$

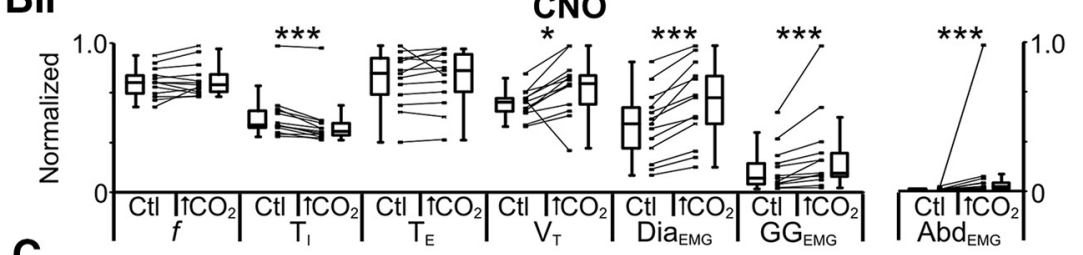

C

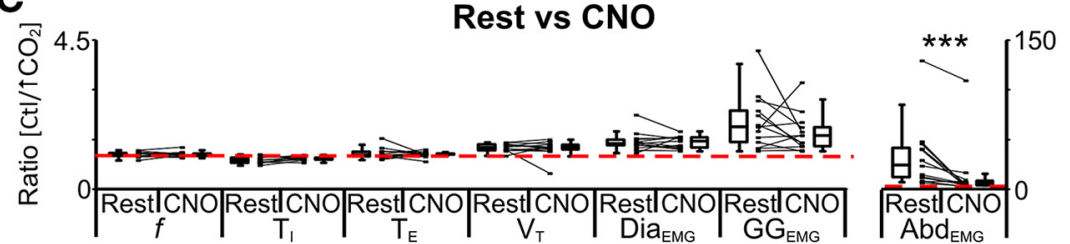

D

\begin{tabular}{|c|c|c|c|c|c|c|c|}
\hline Values: median, IQR & $f$ (breath $/ \mathrm{min}$ ) & $\mathrm{T}_{1}(\operatorname{secs})$ & $T_{E}$ (secs) & $\mathrm{V}_{\mathrm{T}}(\mathrm{mL})$ & $\mathrm{Dia}_{\mathrm{EMG}}$ & $\mathbf{G G}_{\mathrm{EMG}}$ & $\mathrm{Abd}_{\mathrm{EMG}}$ \\
\hline $\begin{array}{r}\text { Rest } \\
9 \% \mathrm{CO}_{2} \\
\mathrm{P}=\end{array}$ & $\begin{array}{c}45.0 .6 .4 \\
47.4,7.9 \\
0.8\end{array}$ & $\begin{array}{c}0.34,0.09 \\
0.30,0.04 \\
0.0008\end{array}$ & $\begin{array}{c}1.0 .0 .2 \\
1.0,0.2 \\
0.4\end{array}$ & $\begin{array}{l}4.4 .0 .6 \\
5.1,0.5 \\
0.0005\end{array}$ & $\begin{array}{c}17.2 .11 .5 \\
23.1,19.5 \\
0.0001\end{array}$ & $\begin{array}{c}9.6 .6 .0 \\
16.5,12.8 \\
0.0001\end{array}$ & $\begin{array}{c}0.2,0.1 \\
3.2,10.8 \\
0.0001\end{array}$ \\
\hline $\begin{array}{r}\mathrm{CNO} \\
\mathrm{CNO} 9 \% \mathrm{CO}_{2} \\
\mathrm{P}=\end{array}$ & $\begin{array}{l}53.3,8.8 \\
52.4,8.4\end{array}$ & $\begin{array}{l}0.35,0.09 \\
0.32,0.06\end{array}$ & $\begin{array}{l}0.8,0.3 \\
0.8,0.2\end{array}$ & $\begin{array}{l}3.6,0.6 \\
4.4,1.2\end{array}$ & $\begin{array}{l}17.1,10.3 \\
23.7,12.2\end{array}$ & $\begin{array}{l}6.1,9.6 \\
8.4,11.0\end{array}$ & $\begin{array}{l}0.2,0.1 \\
0.7,1.1 \\
0.002\end{array}$ \\
\hline $\begin{array}{r}\text { Ratio }\left(9 \% \mathrm{O}_{2}\right) \\
\left.\text { Ratio (CNO } 9 \% \mathrm{CO}_{2}\right)\end{array}$ & $\begin{array}{c}1.0,0.1 \\
1.0,0.1 \\
0.5\end{array}$ & $\begin{array}{c}0.9,0.2 \\
0.9,0.1 \\
0.2\end{array}$ & $\begin{array}{l}1.0 .0 .1 \\
1.0,0.0 \\
0.6\end{array}$ & $\begin{array}{l}1.2,0.2 \\
1.2,0.1 \\
1.0\end{array}$ & $\begin{array}{l}1.2 .0 .1 \\
1.3,0.2 \\
0.7\end{array}$ & $\begin{array}{c}1.9,1.0 \\
1.6,0.6 \\
0.3\end{array}$ & $\begin{array}{c}21.7,29.1 \\
3.0,4.8 \\
0.0002\end{array}$ \\
\hline
\end{tabular}

Figure 6. Hyperpolarizing $\mathrm{pF}_{\mathrm{L}}$ neurons reduced effects of hypercapnia $\left(9 \% \mathrm{CO}_{2}\right)$ on $\mathrm{Abd}_{\mathrm{EMG}}$ only. $\boldsymbol{A}$, Integrated traces from a single experiment: shaded area shows period of hypercapnia. $\boldsymbol{A i}$, Rest. Aii, During application of $\mathrm{CNO}$ to medullary surface (present for entire trace). $\boldsymbol{B}_{3}$ Comparison of respiratory variables before and after hypercapnia in $\mathrm{PF}_{1}: H M_{4} \mathrm{DR}$ rats at rest $(\boldsymbol{B} \boldsymbol{i})$ and in the presence of $\mathrm{CNO}$ ( $\boldsymbol{B i i}$ ). Lines connect data from individual experiments, and box-and-whisker plots show combined data. Data in $\boldsymbol{B} \boldsymbol{i}$ and $\boldsymbol{B i i}$ are normalized to highest value for that parameter, i.e., $f, \mathrm{~T}_{\mathrm{I}}, \mathrm{T}_{\mathrm{E}}, \mathrm{V}_{\mathrm{T}}, \mathrm{GG}_{\mathrm{EMG}}, \mathrm{Dia}_{\mathrm{EMG}}$, or $\mathrm{Abd}_{\mathrm{EMG}}$, regardless of whether it belonged to control or $9 \% \mathrm{CO}_{2}$ group. $\mathrm{C}$, Comparison between ratio changes induced by hypercapnia in $\mathrm{pF}_{L}: \mathrm{HM}_{4} \mathrm{DR}$ rats at rest and in the presence of $\mathrm{CNO}$. Data in $C$ are expressed as ratios of resting values, and red horizontal dashed line represents a ratio of 1. $\boldsymbol{D}$, Table containing median, IQR, and $p$ values, from data represented in $\boldsymbol{B}$. ${ }^{*} p<0.05,{ }^{* *} p<0.01,{ }^{* * *} p<$ 0.005 .

$\bar{X}_{\text {stimulus }}$ value for every rat, were combined into a single dataset. To facilitate graphical comparisons, excluding ratio changes (see above), data were normalized to the highest value in the dataset regardless of whether it belonged to $\bar{X}_{\text {control }}$ or $\bar{X}_{\text {stimulus }}$ group. Therefore the highest value in the dataset, whether it be $\bar{X}_{\text {control }}$ or $\bar{X}_{\text {stimulus }}$, was 1.0.

For the purpose of analysis, active expiration was defined by the presence of bursts of $\mathrm{Abd}_{\mathrm{EMG}}$ activity above tonic levels between inspiratory bursts, similar to previous studies (Pagliardini et al., 2011).

As usually seen in smaller sample sizes $(n<30)$, recorded data were often skewed, and thus were treated as nonparametric, for which the median and interquartile range (IQR) better represent the data than mean, and SD or SE. We used nonparametric tests for our statistical analysis, as these tests make fewer assumptions about the data and would not require us to exclude statistical outliers. Statistical tests are Wilcoxon signed-rank tests unless otherwise stated, with a significance level of $p \leq$ 0.05 . In Results, we have displayed the data as box-and-whisker plots for comparison of group data and as line graphs for individual experiments.

\section{Results}

Targeting of specific parafacial regions By carefully choosing stereotaxic coordinates we were able to target viral injections into two anatomically separate regions that we designate as the parafacial ventral $\left(\mathrm{pF}_{\mathrm{V}}\right)$ and parafacial lateral $\left(\mathrm{pF}_{\mathrm{L}}\right.$; Fig. 2). Using anatomical markers we confirmed the location of our injections and that they were restricted to defined areas with no overlapping transfection of neurons (Fig. $2 B, C$ ). The $\mathrm{pF}_{\mathrm{L}}$ was defined as the area ventral to the lateral edge of the facial nucleus, juxtaposed to the spinal trigeminal tract (Fig. 2Ai,B). The $\mathrm{pF}_{\mathrm{V}}$ was defined as the area ventral to the caudal half of the facial nucleus, between the pyramidal tract and the spinal trigeminal tract (Fig. $2 A i, C, D$ ). In representative individual $40 \mu \mathrm{m}$ sections from the core of the synapsin- $\mathrm{HM}_{4} \mathrm{DR}$ injection site in the $\mathrm{pF}_{\mathrm{L}}$ of different rats, $135 \pm 20$ neurons expressed mCitrine representing $78 \pm 9 \%$ of neurons $(n=3)$. Similarly, in representative individual $40 \mu \mathrm{m}$ sections from the core of the synapsin-AlstR injection site in the $\mathrm{pF}_{\mathrm{V}}$ of different rats, $129 \pm 21$ neurons expressed GFP, representing $76 \pm 6 \%$ of neurons $(n=3)$. Therefore, the transfection efficiencies of the two viruses in each area were similar for both the number of transfected neurons $(p=0.5)$, and the percentage of neurons transfected $(p=$ $0.3)$.

\section{Hyperpolarizing $\mathrm{pF}_{\mathrm{L}}$ neurons at rest had no effect on breathing}

Based on our hypothesis that in adult rat the $\mathrm{pF}_{\mathrm{L}}$ is a conditional expiratory oscillator that is inactive at rest (Janczewski and Feldman, 2006; Pagliardini et al., 2011), we predicted little or no effect of hyperpolarizing $\mathrm{pF}_{\mathrm{L}}$ neurons on resting ventilation. In anesthetized rats at rest transfected with $\mathrm{HM}_{4} \mathrm{DR}$ in the lateral parafacial, i.e., $\mathrm{pF}_{\mathrm{L}}$ : $\mathrm{HM}_{4} \mathrm{DR}$ rats (Fig. 1ix, $x$ ), $\mathrm{CNO}$ increased frequency $(f)$ and decreased expiratory period $\left(T_{E}\right)$, with no significant effect on inspiratory period $\left(\mathrm{T}_{\mathrm{I}}\right)$, tidal volume $\left(\mathrm{V}_{\mathrm{T}}\right), \mathrm{Dia}_{\mathrm{EMG}}$, or $\mathrm{GG}_{\mathrm{EMG}}$; $\mathrm{Abd}_{\mathrm{EMG}}$, silent at rest, remained so after $\mathrm{CNO}(n=13$; Fig. $4 A i, B i, D)$.

We assessed whether the effects of $\mathrm{CNO}$ on resting ventilation were due exclusively to actions via $\mathrm{pF}_{\mathrm{L}}: \mathrm{HM}_{4} \mathrm{DR}$-transfected neurons or confounded by nonspecific effects. In anesthetized rats at rest with no $\mathrm{HM}_{4} \mathrm{DRs}$ (i.e., $\mathrm{pF}_{\mathrm{V}}$ :AlstR rats; Fig. 1 xi), $\mathrm{CNO}$ increased $f$ and decreased $\mathrm{T}_{\mathrm{E}}$ with no significant effect on $\mathrm{T}_{\mathrm{I}}, \mathrm{V}_{\mathrm{T}}$, $\mathrm{Dia}_{\mathrm{EMG}}$, and $\mathrm{GG}_{\mathrm{EMG}} ; \mathrm{Abd}_{\mathrm{EMG}}$, silent at rest, remained so after CNO ( $n=7$; Fig. 4Aii,Bii,D). To determine whether hyperpolarizing $\mathrm{pF}_{\mathrm{L}}: \mathrm{HM}_{4} \mathrm{DR}$ neurons had additional effects on $f$ and $\mathrm{T}_{\mathrm{E}}$ beyond the nonspecific effects seen in $\mathrm{pF}_{\mathrm{V}}$ :AlstR rats, we computed for each measured variable, i.e., $f, \mathrm{~T}_{\mathrm{I}}, \mathrm{T}_{\mathrm{E}}, \mathrm{V}_{\mathrm{T}}, \mathrm{Dia}_{\mathrm{EMG}}$, $\mathrm{GG}_{\mathrm{EMG}}$, and $\mathrm{Abd}_{\mathrm{EMG}}$, the ratio of its value after $\mathrm{CNO}$ divided by 
its value before $\mathrm{CNO}$, i.e., "ratio change" (see Materials and Methods, Data analysis and statistics), in rats with versus without $\mathrm{HM}_{4} \mathrm{DRs}$, i.e., $\mathrm{pF}_{\mathrm{L}}: \mathrm{HM}_{4} \mathrm{DR} \quad[$ rest + $\mathrm{CNO}) /$ rest] vs $\mathrm{pF}_{\mathrm{V}}$ :AlstR [(rest $\left.+\mathrm{CNO}\right) /$ rest]. The ratio changes between the $\mathrm{pF}_{\mathrm{L}}$ : $\mathrm{HM}_{4} \mathrm{DR}$ and $\mathrm{pF}_{\mathrm{V}}$ :AlstR rat groups were not significantly different for any variable $(n=20$; Kruskal-Wallis; Fig. 4C,D). As the effects of $\mathrm{CNO}$ on resting ventilation were similar whether $\mathrm{HM}_{4} \mathrm{DRs}$ were present or not, the $\mathrm{CNO}$-induced changes at rest were not due to activation of $\mathrm{HM}_{4} \mathrm{DRs}$, but instead to some nonspecific effect of $\mathrm{CNO}$ or its vehicle. In subsequent experiments, to control for nonspecific effects of CNO, we compared the effects of $\mathrm{CNO}$ on the responses to different stimuli in rats without $\mathrm{HM}_{4} \mathrm{DRs}$ to rats with $\mathrm{HM}_{4}$ DRs.

\section{Disinhibition of $\mathrm{pF}_{\mathrm{L}}$ has profound} effects on respiration

$\mathrm{pF}_{\mathrm{L}}$ neurons can be disinhibited by injection of a mixture of the $\mathrm{GABA}_{\mathrm{A}}$ and glycine antagonists bicuculline and strychnine $\left(\mathrm{B}+\mathrm{S}_{\mathrm{pF}_{\mathrm{L}}}\right)$, which results in a transformation in breathing from passive to active expiration (Pagliardini et al., 2011). Hyperpolarization of $\mathrm{pF}_{\mathrm{L}}: \mathrm{HM}_{4} \mathrm{DR}$ neurons should reduce the depolarizing effects of $\mathrm{B}+\mathrm{S}_{\mathrm{pFL}}$. In anesthetized rats at rest transfected with $\mathrm{HM}_{4} \mathrm{DR}$ in the lateral parafacial, i.e., $\mathrm{pF}_{\mathrm{L}}: \mathrm{HM}_{4} \mathrm{DR}$ rats (Fig. $1 i, i i), \mathrm{B}+\mathrm{S}_{\mathrm{pFL}}$ decreased $f$ and $\mathrm{T}_{\mathrm{I}}$; increased $\mathrm{T}_{\mathrm{E}}, \mathrm{V}_{\mathrm{T}}, \mathrm{Dia}_{\mathrm{EMG}}$, and $\mathrm{GG}_{\mathrm{EMG}}$; and induced expiratory-related $\operatorname{Abd}_{\mathrm{EMG}}(n=$ 13; Fig. $5 A i, B i, D)$, the latter a signature of active expiration, q.v. (Pagliardini et al., 2011). The same trends ( $n=13$; Fig. 5 Aii$, B i i, D)$ were seen in the presence of $\mathrm{CNO}$ (Fig. 1ix, $x$ ). However, in the presence of $\mathrm{CNO}$ following $\mathrm{B}+\mathrm{S}_{\mathrm{pF}_{\mathrm{L}}}$, the ratio changes $\left[\left(\mathrm{B}+\mathrm{S}_{\mathrm{pF} L}+\mathrm{CNO}\right) /(\mathrm{Ctl}+\right.$ $\mathrm{CNO})]$ for all measured variables were significantly closer to 1 than those in the absence of $\mathrm{CNO}\left[\mathrm{B}+\mathrm{S}_{\mathrm{pF}_{\mathrm{L}}} / \mathrm{Ctl}\right](n=13$; Fig. $5 C, D)$. As $\mathrm{CNO}$ in the absence of $\mathrm{HM}_{4} \mathrm{DRs}$ did not affect the response to $\mathrm{B}+\mathrm{S}_{\mathrm{pF}_{\mathrm{L}}}$ (see next paragraph), these results indicate that hyperpolarizing $\mathrm{pF}_{\mathrm{L}}$ : $\mathrm{HM}_{4} \mathrm{DR}$ neurons with $\mathrm{CNO}$ attenuated the effects of $\mathrm{B}+\mathrm{S}_{\mathrm{pFL}}$ on all variables.

CNO does not affect the response to $\mathrm{B}+\mathrm{S}_{\mathrm{pF}_{\mathrm{L}}}$ in the absence of CNO-sensitive $\mathrm{HM}_{4} \mathrm{DRs}$

In anesthetized rats at rest with no $\mathrm{HM}_{4} \mathrm{DRs}$, i.e., $\mathrm{pF}$ : AlstR rats (Fig. 1iii), $\mathrm{B}+\mathrm{S}_{\mathrm{pF}_{\mathrm{L}}}$ decreased $f(p=0.02)$ and $\mathrm{T}_{\mathrm{I}}(p=0.02)$, increased $\mathrm{T}_{\mathrm{E}}(p=0.008), \mathrm{V}_{\mathrm{T}}(p=0.02), \operatorname{Dia}_{\mathrm{EMG}}(p=0.008)$, and $\mathrm{GG}_{\mathrm{EMG}}(p=0.008)$, and induced expiratory-related $\mathrm{Abd}_{\mathrm{EMG}}$ $(p=0.02 ; n=7$; data not shown). The same trends $(n=7 ; f$ : $p=0.02 ; \mathrm{T}_{\mathrm{I}}: p=0.02 ; \mathrm{T}_{\mathrm{E}}: p=0.008 ; \mathrm{V}_{\mathrm{T}}: p=0.02 ; \mathrm{Dia}_{\mathrm{EMG}}: p=$ 0.008 GG $_{\mathrm{EMG}}: p=0.008$ Abd $_{\mathrm{EMG}}: p=0.02$; data not shown) were seen in the presence of CNO (Fig. 1xi). Importantly, in the ${ }^{* *} p<0.01,{ }^{* * *} p<0.005$.
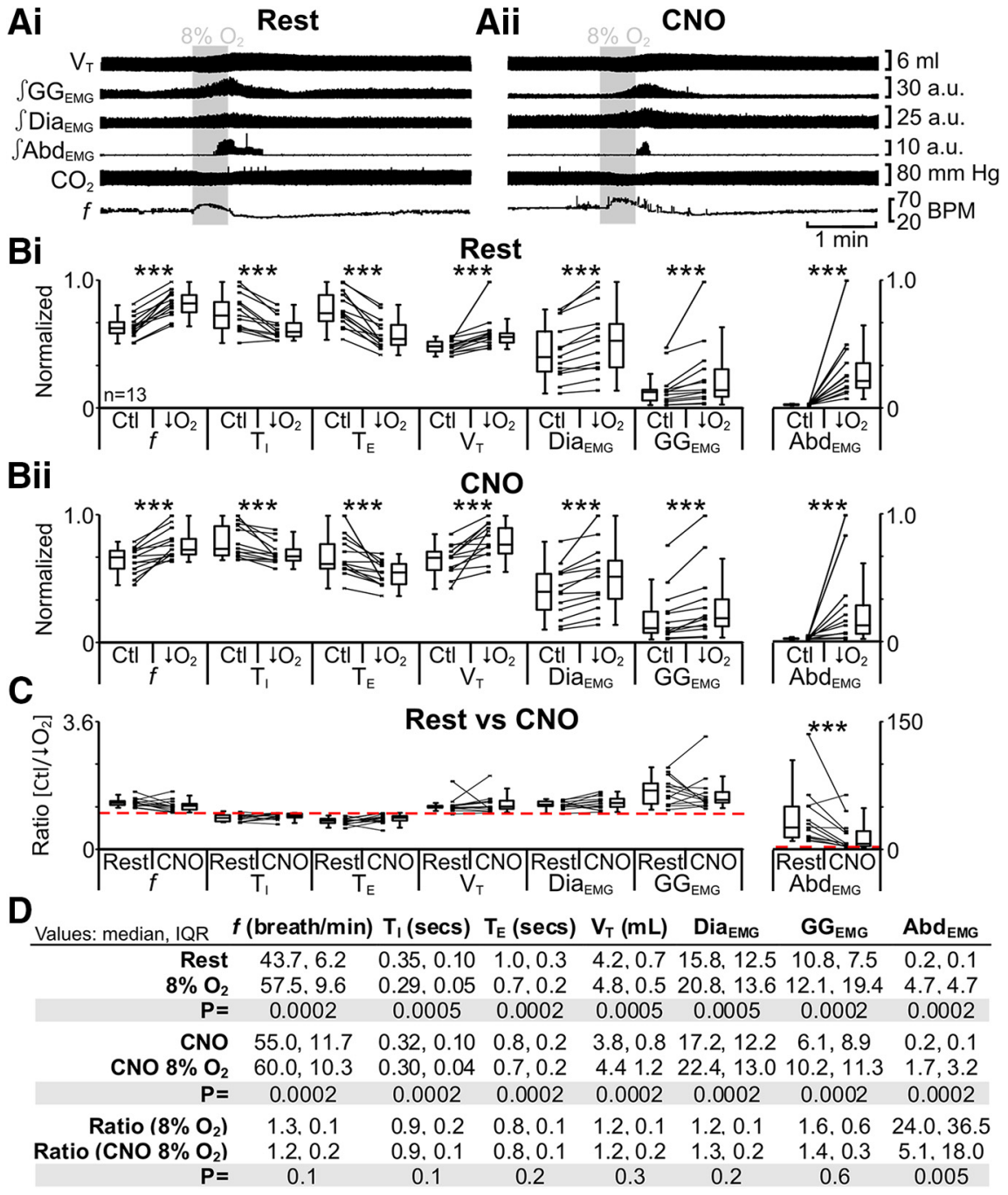

Figure 7. Hyperpolarizing $\mathrm{pF}_{\mathrm{L}}$ neurons reduced effects of hypoxia $\left(8 \% \mathrm{O}_{2}\right)$ on $\mathrm{Abd}_{\mathrm{EMG}}$ only. $\boldsymbol{A}$, Integrated traces from a single experiment: shaded area shows period of hypoxia. Ai, Rest. Aii, During application of CNO to medullary surface of $\mathrm{CNO}(\boldsymbol{B}$ ii). Lines connect data from individual experiments, and box-and-whisker plots show combined in $\mathbf{B i}$ and $B i i$ are normalized to highest value for that parameter, i.e., $f, T_{1}, T_{E}, V_{T}, G G_{E M G}, D i a_{E M G}$ or $A_{b d} d_{E M G}$ $\mathrm{PF} \cdot \mathrm{HM} \mathrm{DR}$ rats a rest and in to dashed line represents a ratio of 1 . D, Table containing median, IQR, and $p$ values, from data represented in $\boldsymbol{B} .{ }^{*} p<0.05$,

presence of CNO following $\mathrm{B}+\mathrm{S}_{\mathrm{pF}_{\mathrm{L}}}$, the ratio changes $\left[\left(\mathrm{B}+\mathrm{S}_{\mathrm{pF}}\right.\right.$ $+\mathrm{CNO}) /(\mathrm{Ctl}+\mathrm{CNO})]$ for all measured variables were not significantly different to those in the absence of $\mathrm{CNO}\left[\mathrm{B}+\mathrm{S}_{\mathrm{pF}_{\mathrm{L}}} / \mathrm{Ctl}\right]$ $\left(n=7 ; f: p=0.8 ; \mathrm{T}_{\mathrm{I}}: p=0.2 ; \mathrm{T}_{\mathrm{E}}: p=0.7 ; \mathrm{V}_{\mathrm{T}}: p=1.0 ; \mathrm{Dia}_{\mathrm{EMG}}: p=\right.$ $1.0 ; \mathrm{GG}_{\mathrm{EMG}}: p=0.7 ; \operatorname{Abd}_{\mathrm{EMG}}: p=0.6$; data not shown). Thus any nonspecific effects of $\mathrm{CNO}$ on $f$ did not affect the response to $\mathrm{B}+$ $\mathrm{S}_{\mathrm{pF}_{\mathrm{L}}}$.

Hyperpolarizing $\mathrm{pF}_{\mathrm{L}}$ neurons during hypercapnia only affect Abd ${ }_{\text {EMG }}$

Hypercapnia increases ventilation by increasing $\mathrm{V}_{\mathrm{T}}$ without a concurrent change in $f$ (Stunden et al., 2001; Putnam et al., 2005), and elicits robust expiratory-related abdominal activity (Iizuka and Fregosi, 2007; Marina et al., 2010), i.e., active expiration. These effects were reduced by hyperpolarizing parafacial neurons (Marina et al., 2010). In anesthetized rats at rest transfected with 


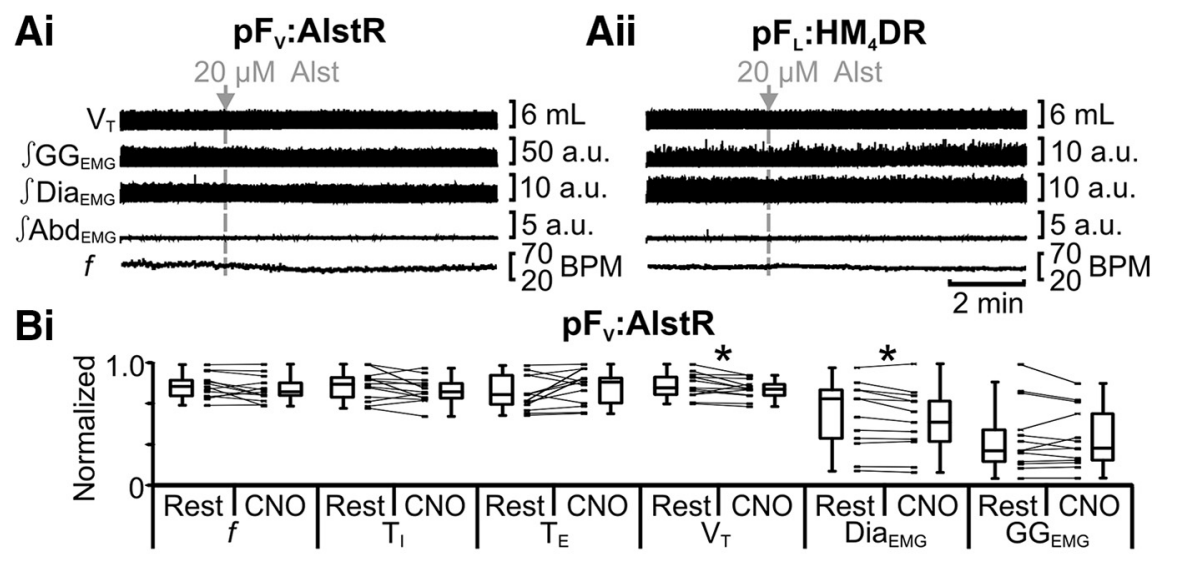

Bii

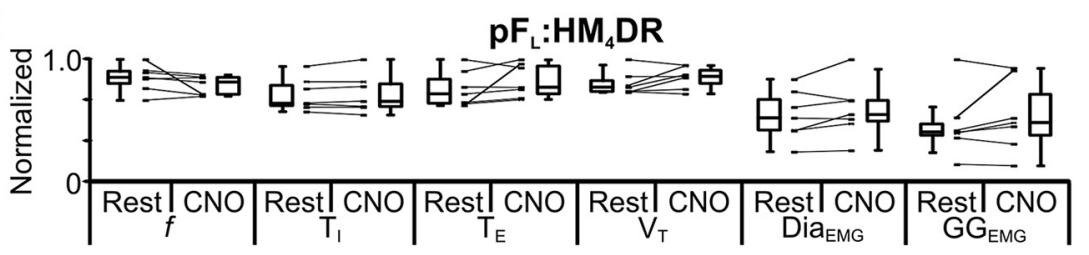

C

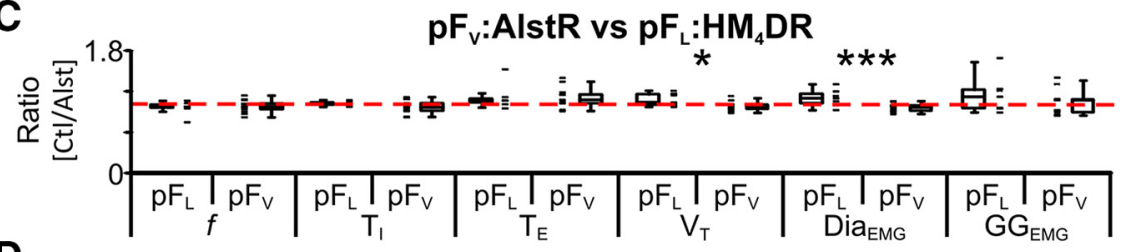

D

\begin{tabular}{|c|c|c|c|c|c|c|}
\hline $\begin{array}{l}\text { Values: } \\
\text { median, IQR }\end{array}$ & $f$ (breath/m in) & $T_{1}$ (secs) & $\mathrm{T}_{\mathrm{E}}(\operatorname{secs})$ & $V_{T}(m L)$ & DiamG & $\mathbf{G G}_{\mathrm{EMG}}$ \\
\hline Rest $\left(p F_{L}\right)$ & $48.0,5.4$ & $0.3,0.1$ & $0.9,0.2$ & $4.2,0.5$ & $15.9,7.2$ & $5.5,1.2$ \\
\hline Alst $\left(p F_{L}\right)$ & $45.8,7.5$ & $0.3,0.1$ & $1.0,0.3$ & $4.7,0.6$ & $16.7,4.9$ & $6.5,4.2$ \\
\hline$P=$ & 0.1 & 0.7 & 0.2 & 0.4 & 0.2 & 0.4 \\
\hline Rest $\left(p F_{v}\right)$ & $46.7,7.5$ & $0.3,0.1$ & $1.0,0.3$ & $3.6,0.7$ & $24.0,15.8$ & $11.6,11.0$ \\
\hline Alst $\left(p F_{v}\right)$ & $44.1,6.1$ & $0.3,0.1$ & $1.1,0.3$ & $3.5,0.4$ & $21.6,12.8$ & $12.4,16.0$ \\
\hline$P=$ & 0.2 & 0.2 & 0.09 & 0.04 & 0.03 & 0.7 \\
\hline Ratio ( $\left.p F_{L}\right)$ & $1.0,0.0$ & $1.0,0.0$ & $1.1,0.1$ & $1.02,0.12$ & $1.1,0.1$ & $1.0,0.2$ \\
\hline Ratio $\left(p F_{v}\right)$ & $1.0,0.1$ & $1.0,0.1$ & $1.1,0.1$ & $0.96,0.07$ & $0.90,0.1$ & $1.1,0.2$ \\
\hline$P=$ & 0.8 & 0.2 & 1.0 & 0.02 & 0.005 & 0.2 \\
\hline
\end{tabular}

Figure 8. $\quad \mathrm{pF}_{\mathrm{v}}$ provides facilitative drive to respiration at rest. $A$, Integrated traces from a single experiment: gray arrows and vertical dashed lines show the beginning of Alst injection in $\mathrm{pF}$ :AlstR rats $(\boldsymbol{A} \boldsymbol{i})$, or in rats lacking AlstRs, i.e., $\mathrm{pF}_{\mathrm{L}}: \mathrm{HM}_{4} \mathrm{DR}$ rats (Aii). $\boldsymbol{B}$, Comparison of respiratory variables before and after Alst in $\mathrm{pF} \mathrm{F}_{\mathrm{v}}$ :AlstR rats $(\boldsymbol{B \boldsymbol { B }})$ and $\mathrm{pF}_{\mathrm{L}}: \mathrm{HM}_{4} \mathrm{DR}$ rats $(\boldsymbol{B i \boldsymbol { i }})$. Lines connect data from individual experiments, and box-and-whisker plots show combined data. Data in $\boldsymbol{B i}$ and $\boldsymbol{B i i}$ are normalized to highest value for that parameter, i.e., $f, \mathrm{~T}_{\mathrm{I}} \mathrm{T}_{\mathrm{E}}, \mathrm{V}_{\mathrm{T}}, \mathrm{GG}_{\mathrm{EMG}}, \mathrm{Dia}_{\mathrm{EMG}}$, or $\mathrm{Abd}_{\mathrm{EMG}}$, regardless of whether it belonged to control or Alst group. $C$, Comparison of ratio changes between effects of Alst on $\mathrm{PF}_{\mathrm{L}}: \mathrm{HM}_{4} \mathrm{DR}$ and $\mathrm{pF} \mathrm{V}_{\mathrm{V}}: \mathrm{AlstR}$ rats. Box-andwhisker plots show combined data, with data points from individual experiments. Data in $C$ are expressed as ratios of resting values, and red horizontal dashed line represents a ratio of 1 . $D$, Table containing median, IQR, and $p$ values, from data represented in $\boldsymbol{A} .{ }^{*} p<0.05,{ }^{* *} p<0.01,{ }^{* * *} p<0.005$.

$\mathrm{HM}_{4} \mathrm{DR}$ in the lateral parafacial, i.e., $\mathrm{pF}_{\mathrm{L}}$ : $\mathrm{HM}_{4} \mathrm{DR}$ rats (Fig. $1 i$,ii), hypercapnia did not affect $f$; decreased $\mathrm{T}_{\mathrm{I}}$; did not affect $\mathrm{T}_{\mathrm{E}}$; increased $\mathrm{V}_{\mathrm{T}}, \mathrm{Dia}_{\mathrm{EMG}}$, and $\mathrm{GG}_{\mathrm{EMG}}$; and induced expiratory-related $\operatorname{Abd}_{\mathrm{EMG}}(n=13$; Fig. $6 A i, B i, D)$. The same trends $(n=13$; Fig. $6 \mathrm{Aii}, \mathrm{Bii}, \mathrm{D})$ were seen in the presence of $\mathrm{CNO}$ (Fig. 1ix, x). However, in the presence of $\mathrm{CNO}$ during hypercapnia only the ratio change [(hypercapnia $+\mathrm{CNO}) /(\mathrm{Ctl}+\mathrm{CNO})]$ for expiratory-related $\mathrm{Abd}_{\mathrm{EMG}}$ was significantly closer to 1 than the ratio change in the absence of $\mathrm{CNO}$ [hypercapnia/Ctl] $(n=13$; Fig. $6 C, D)$. CNO in the absence of $\mathrm{HM}_{4} \mathrm{DRs}$ did not affect the response to hypercapnia (see next paragraph). Thus hyperpolarizing $\mathrm{pF}_{\mathrm{L}}: \mathrm{HM}_{4} \mathrm{DR}$ neurons with $\mathrm{CNO}$ attenuated the effects of hypercapnia only on expiratory-related $\mathrm{Abd}_{\mathrm{EMG}}$.
CNO does not affect the response to hypercapnia in the absence of CNO-sensitive $\mathrm{HM}_{4} \mathrm{DRs}$

In anesthetized rats at rest with no $\mathrm{HM}_{4} \mathrm{DRs}$, i.e., $\mathrm{pF}_{\mathrm{V}}$ :AlstR rats (Fig. 1 iii), hypercapnia did not affect $f(p=1.0)$; decreased $\mathrm{T}_{\mathrm{I}}(p=0.04)$; did not affect $\mathrm{T}_{\mathrm{E}}$ $(p=0.6)$; increased $\mathrm{V}_{\mathrm{T}}(p=0.02)$, Di$\mathrm{a}_{\mathrm{EMG}}(p=0.008)$, and $\mathrm{GG}_{\mathrm{EMG}}(p=$ $0.008)$; and induced expiratory-related $\operatorname{Abd}_{\mathrm{EMG}}(p=0.008 ; n=7$; data not shown). The same trends $(n=7 ; f: p=$ $0.6 ; \mathrm{T}_{\mathrm{I}}: p=0.02 ; \mathrm{T}_{\mathrm{E}}: p=0.3 ; \mathrm{V}_{\mathrm{T}}: p=0.02$; $\mathrm{Dia}_{\mathrm{EMG}}: p=0.008$; GG $\mathrm{EMG}: p=0.008$; $\operatorname{Abd}_{\mathrm{EMG}}: p=0.008$; data not shown) were seen in the presence of CNO (Fig. 1xi). Importantly, during hypercapnia in the presence of $\mathrm{CNO}$, the ratio changes [ (hypercapnia $+\mathrm{CNO}) /(\mathrm{Ctl}$ in $\mathrm{CNO})]$ for all measured variables were not significantly different to those in the absence of CNO [hypercapnia/Ctl] $\left(n=7 ; f: p=1.0 ; \mathrm{T}_{\mathrm{I}}\right.$ : $p=0.3 ; \mathrm{T}_{\mathrm{E}}: p=0.7 ; \mathrm{V}_{\mathrm{T}}: p=0.9 ; \operatorname{Dia}_{\mathrm{EMG}}:$ $p=0.4 ; \mathrm{GG}_{\mathrm{EMG}}: p=0.1 ; \mathrm{Abd}_{\mathrm{EMG}}: p=0.8$; data not shown). Thus any nonspecific effects of CNO on $f$ did not affect the response to hypercapnia.

\section{Hyperpolarizing $\mathrm{pF}_{\mathrm{L}}$ neurons}

during hypoxia only affect $\mathrm{Abd}_{\mathrm{EMG}}$

Hypoxia increases ventilation by increasing $\mathrm{V}_{\mathrm{T}}$ with a concurrent change in $f$, and elicits robust expiratory-related abdominal activity (Sherrey et al., 1988; Iizuka and Fregosi, 2007). In anesthetized rats at rest transfected with $\mathrm{HM}_{4} \mathrm{DR}$ in the lateral parafacial, i.e., $\mathrm{pF}_{\mathrm{L}}: \mathrm{HM}_{4} \mathrm{DR}$ rats (Fig. 1i,ii), hypoxia increased $f$; decreased $T_{I}$ and $T_{E}$; increased $V_{T}$, Di$\mathrm{a}_{\mathrm{EMG}}$, and $\mathrm{GG}_{\mathrm{EMG}} ;$ and induced expiratory-related $\operatorname{Abd}_{\mathrm{EMG}}(n=13$; Fig. $7 A i, B i, D)$. The same trends $(n=13$; Fig. $7 A i i, B i, D)$ were seen in the presence of CNO (Fig. 1ix;x). However, in the presence of CNO during hypoxia only the ratio change [(hypoxia $+\mathrm{CNO}) /(\mathrm{Ctl}+$ $\mathrm{CNO})]$ for expiratory-related $\mathrm{Abd}_{\mathrm{EMG}}$ was significantly closer to 1 than the ratio change in the absence of CNO [hypoxia/Ctl] $(n=13$; Fig. $7 C, D)$. CNO in the absence of $\mathrm{HM}_{4} \mathrm{DRs}$ did not affect the response to hypoxia (see next paragraph). Thus hyperpolarizing $\mathrm{pF}_{\mathrm{L}}: \mathrm{HM}_{4} \mathrm{DR}$ neurons with $\mathrm{CNO}$ only attenuated the effects of hypoxia on expiratory-related $\mathrm{Abd}_{\mathrm{EMG}}$.

CNO does not affect response to hypoxia in absence of CNOsensitive $\mathrm{HM}_{4} \mathrm{DRs}$

In anesthetized rats at rest with no $\mathrm{HM}_{4} \mathrm{DRs}$, i.e., $\mathrm{pF}_{\mathrm{V}}$ :AlstR rats (Fig. 1iii), hypoxia increased $f(p=0.02)$; decreased $\mathrm{T}_{\mathrm{I}}(p=0.04)$ and $\mathrm{T}_{\mathrm{E}}(p=0.04)$; increased $\mathrm{V}_{\mathrm{T}}(p=0.02), \operatorname{Dia}_{\mathrm{EMG}}(p=0.008)$, and $\mathrm{GG}_{\mathrm{EMG}}(p=0.008)$; and induced expiratory-related $\mathrm{Abd}_{\mathrm{EMG}}$ $(p=0.008 ; n=7 ;$ data not shown). The same trends ( $n=7 ; f: p=$ 
$0.02 ; \mathrm{T}_{\mathrm{I}}: p=0.04 ; \mathrm{T}_{\mathrm{E}}: p=0.04 ; \mathrm{V}_{\mathrm{T}}: p=$ 0.02 ; $\mathrm{Dia}_{\mathrm{EMG}}: p=0.008$ GG $_{\mathrm{EMG}}: p=$ $0.008 ; \operatorname{Abd}_{\mathrm{EMG}}: p=0.008$; data not shown) were seen in the presence of CNO (Fig. 1xi). Importantly, in the presence of $\mathrm{CNO}$, during hypoxia, the ratio changes $[($ hypoxia $+\mathrm{CNO}) /(\mathrm{Ctl}$ $+\mathrm{CNO})]$ for all measured variables were not significantly different to the ratio changes in the absence of CNO [hypoxia/Ctl] $\left(n=7 ; f: p=0.5 ; \mathrm{T}_{\mathrm{I}}: p=0.1\right.$; $\mathrm{T}_{\mathrm{E}}: p=0.9 ; \mathrm{V}_{\mathrm{T}}: p=0.3 ; \operatorname{Dia}_{\mathrm{EMG}}: p=0.9$; $\mathrm{GG}_{\mathrm{EMG}}: p=0.2 ; \operatorname{Abd}_{\mathrm{EMG}}: p=0.7$; data not shown). Thus any nonspecific effect of CNO on $f$ did not affect the response to hypoxia.

\section{Hyperpolarizing $\mathrm{pF}_{\mathrm{V}}$ neurons at rest decrease $V_{T}$ and Dia}

Neurons ventral to the facial nucleus are hypothesized to provide significant ventilatory drive at rest (Smith et al., 1989; Ellenberger and Feldman, 1990; Nattie, 2000; Guyenet et al., 2005), and hyperpolarizing neurons ventral to the facial nucleus decrease resting ventilation (Nattie and Li, 2002; Li et al., 2006) and reduce phrenic nerve activity (Marina et al., 2010). Thus we predicted that hyperpolarizing $\mathrm{pF}_{\mathrm{V}}$ neurons would reduce $\mathrm{Dia}_{\mathrm{EMG}}$ and consequently $\mathrm{V}_{\mathrm{T}}$. In anesthetized rats at rest transfected with AlstR in the ventral parafacial, i.e., $\mathrm{pF}_{\mathrm{V}}$ :AlstR rats (Fig. 1vi,vii), allatostatin bilaterally injected into the $\mathrm{pF}_{\mathrm{V}}$ (Alst) decreased $\mathrm{V}_{\mathrm{T}}$ and $\mathrm{Dia}_{\mathrm{EMG}}$, with no significant effect on $f, \mathrm{~T}_{\mathrm{I}}, \mathrm{T}_{\mathrm{E}}$, and $\mathrm{GG}_{\mathrm{EMG}} ; \mathrm{Abd}_{\mathrm{EMG}}$, silent at rest, remained so after Alst $(n=13$; Fig. $8 A i, B i, D)$.

We assessed whether the effects of injecting Alst into the $\mathrm{pF}_{\mathrm{V}}$ on resting ventilation were due exclusively to actions via $\mathrm{pF}_{\mathrm{V}}$ :AlstR neurons or confounded by nonspecific effects of Alst or vehicle. In anesthetized rats at rest with no AlstRs, i.e., $\mathrm{pF}_{\mathrm{L}}: \mathrm{HM}_{4} \mathrm{DR}$ rats (Fig. $1 v$ ), Alst did not affect $f, \mathrm{~T}_{\mathrm{I}}, \mathrm{T}_{\mathrm{E}}, \mathrm{V}_{\mathrm{T}}, \mathrm{Dia}_{\mathrm{EMG}}$, and $\mathrm{GG}_{\mathrm{EMG}} ; \mathrm{Abd}_{\mathrm{EMG}}$, silent at rest, remained so after Alst $(n=7$; Fig. $8 A i i, B i i, D)$. Therefore, following Alst under resting conditions only the ratio changes, i.e., $\mathrm{pF}_{\mathrm{V}}$ :AlstR $[($ rest + Alst $) /$ rest $]$ vs $\mathrm{pF}_{\mathrm{L}}: \mathrm{HM}_{4} \mathrm{DR}[($ rest + Alst $) /$ rest], for $\mathrm{V}_{\mathrm{T}}$ and $\mathrm{Dia}_{\mathrm{EMG}}$ in $\mathrm{pF}_{\mathrm{V}}$ :AlstR rats were significantly different to those in $\mathrm{pF}_{\mathrm{L}}: \mathrm{HM}_{4} \mathrm{DR}$ rats $(n=20$; Kruskal-Wallis; Fig. $8 C, D)$. Thus hyperpolarizing $\mathrm{pF}_{\mathrm{V}}$ :AlstR neurons reduced $\mathrm{V}_{\mathrm{T}}$ and $\mathrm{Dia}_{\mathrm{EMG}}$, consistent with the hypothesis that the $\mathrm{pF}_{\mathrm{V}}$ contributes to respiratory drive at rest (Smith et al., 1989; Ellenberger and Feldman, 1990).

Hyperpolarizing $\mathrm{pF}_{\mathrm{V}}$ neurons during $\mathrm{B}+\mathrm{S}_{\mathrm{pF}_{\mathrm{L}}}$ only attenuates $\mathrm{Abd}_{\mathrm{EMG}}$

We wanted to ascertain if, and how, the $\mathrm{pF}_{\mathrm{L}}$ and $\mathrm{pF}_{\mathrm{V}}$ interact. Thus we hyperpolarized $\mathrm{pF}_{\mathrm{V}}$ neurons followed by $\mathrm{B}+\mathrm{S}_{\mathrm{pF}}$. In anesthetized rats at rest transfected with AlstR in the ventral parafacial, i.e., $\mathrm{pF}_{\mathrm{V}}$ :AlstR rats (Fig. 1 ii, iii), $\mathrm{B}+\mathrm{S}_{\mathrm{pF}}$ decreased $f$ and $\mathrm{T}_{\mathrm{I}}$;

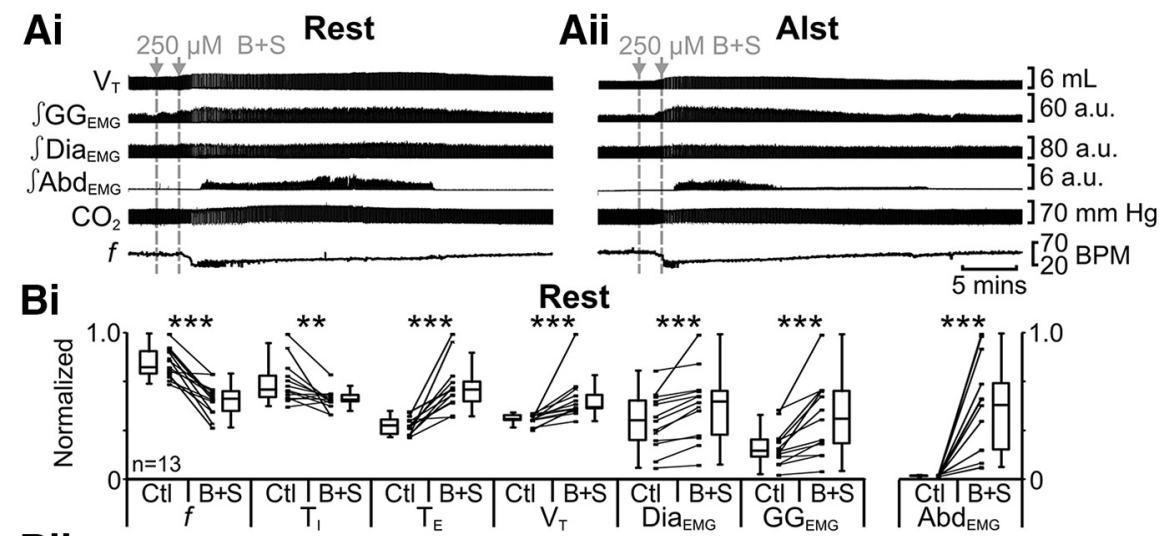
Bii Alst
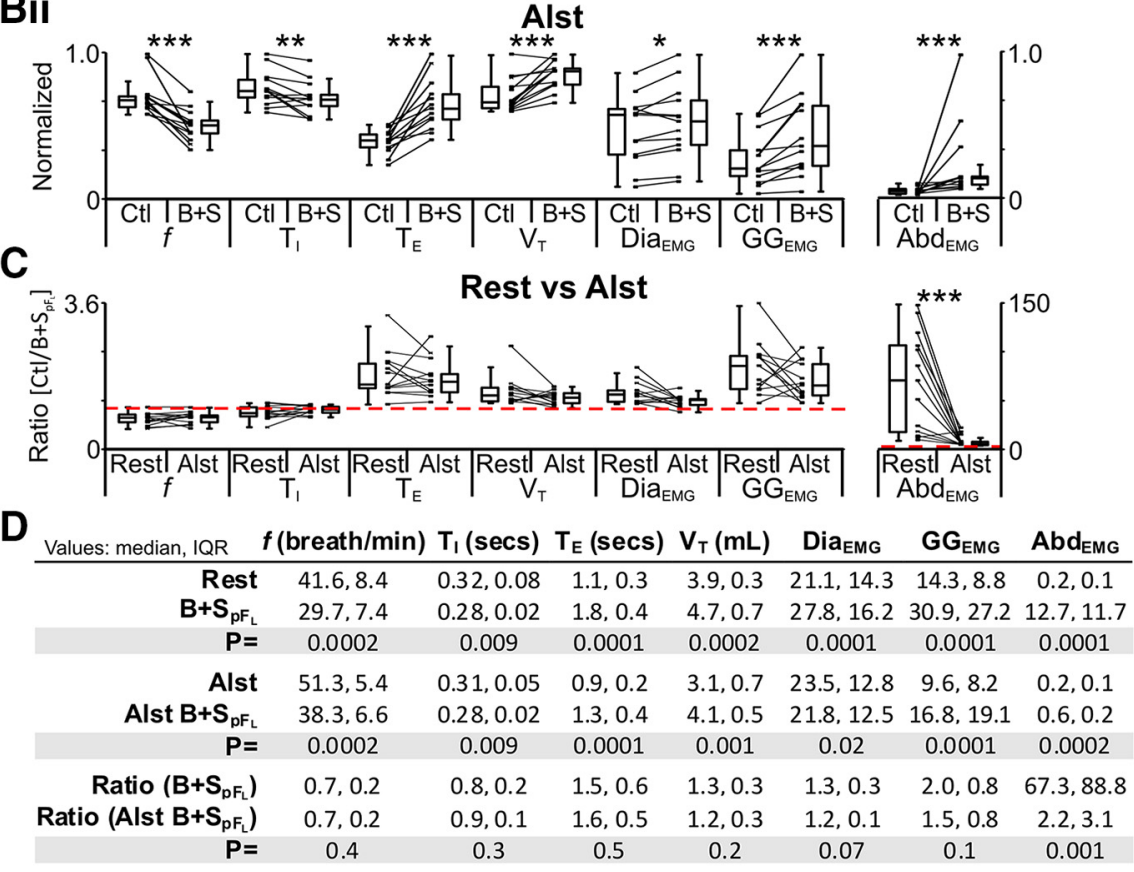

Figure 9. Hyperpolarizing $\mathrm{pF}_{\mathrm{V}}$ neurons reduced effects of disinhibition of $\mathrm{pF}_{\mathrm{L}}\left(\mathrm{B}+\mathrm{S}_{\mathrm{PF}}\right)$ on $\mathrm{Abd}_{\mathrm{EMG}}$ only. $A$, Integrated traces from a single experiment: gray arrows and vertical dashed lines represent pipette placement for unilateral and bilateral $B+S_{P F_{L}}$ ats at rest $(\boldsymbol{B i})$ and in the presence of Alst (Bii). Lines connect data from individual experiments, and box-and-whisker plots show mbined data. Data in $\mathbf{B i}$ and $\mathbf{B i i}$ are normalized to highest value for that parameter, i.e., $f, \mathrm{~T}_{\mathrm{I}}, \mathrm{T}_{\mathrm{E}}, \mathrm{V}_{\mathrm{T}}, \mathrm{GG}_{\mathrm{EMG}}, \mathrm{Dia}_{\mathrm{EMG}}$, or $\mathrm{Abd}_{\mathrm{EMG}}$ $\mathrm{pF}_{\mathrm{v}}$ :AlstR rats at rest and in the presence of Alst. Data in $C$ are expressed as ratios of resting values, and red horizontal dashed line represents a ratio of 1.D, Table containing median, IQR, and $p$ values, from data represented in $\boldsymbol{B} .{ }^{*} p<0.05,{ }^{* *} p<0.01,{ }^{* * *} p<0.005$.

increased $\mathrm{T}_{\mathrm{E}}, \mathrm{V}_{\mathrm{T}}, \mathrm{Dia}_{\mathrm{EMG}}$, and $\mathrm{GG}_{\mathrm{EMG}}$; and induced expiratoryrelated $\operatorname{Abd}_{\mathrm{EMG}}(n=13$; Fig. $9 A i, B i, D)$. The same trends $(n=13$; Fig. $9 A$ Ai,Bii,D) were seen in the presence of Alst (Fig. 1vi,vii). However, in the presence of Alst following $\mathrm{B}+\mathrm{S}_{\mathrm{pF}}$ only the ratio change $\left[\left(\mathrm{B}+\mathrm{S}_{\mathrm{pF}}+\mathrm{Alst}\right) /(\mathrm{Ctl}+\mathrm{Alst})\right]$ for expiratory-related $\mathrm{Abd}_{\mathrm{EMG}}$ was significantly closer to 1 than the ratio change in the absence of Alst [B $\left.+\mathrm{S}_{\mathrm{pF}_{\mathrm{L}}} / \mathrm{Ctl}\right](n=13$; Fig. $9 C, D)$. Alst in the absence of AlstRs did not affect the response to $B+S_{p F_{L}}$ (see next paragraph). Thus although $\mathrm{B}+\mathrm{S}_{\mathrm{pF}_{\mathrm{L}}}$ had profound effects on breathing patterns, the sole effect of hyperpolarizing $\mathrm{pF}_{\mathrm{V}}$ neurons was to reduce the $\mathrm{B}+\mathrm{S}_{\mathrm{pF}_{\mathrm{L}}}$-induced increase in expiratory-related $\mathrm{Abd}_{\mathrm{EMG}}$.

Alst does not affect the response to $\mathrm{B}+\mathrm{S}_{\mathrm{pF}_{\mathrm{L}}}$ in the absence of AlstRs

In anesthetized rats at rest with no AlstRs, i.e., $\mathrm{pF}_{\mathrm{L}}: \mathrm{HM}_{4} \mathrm{DR}$ rats (Fig. 1i), B $+\mathrm{S}_{\mathrm{pF}_{\mathrm{L}}}$ decreased $f(p=0.02)$ and $\mathrm{T}_{\mathrm{I}}(p=0.04)$; 


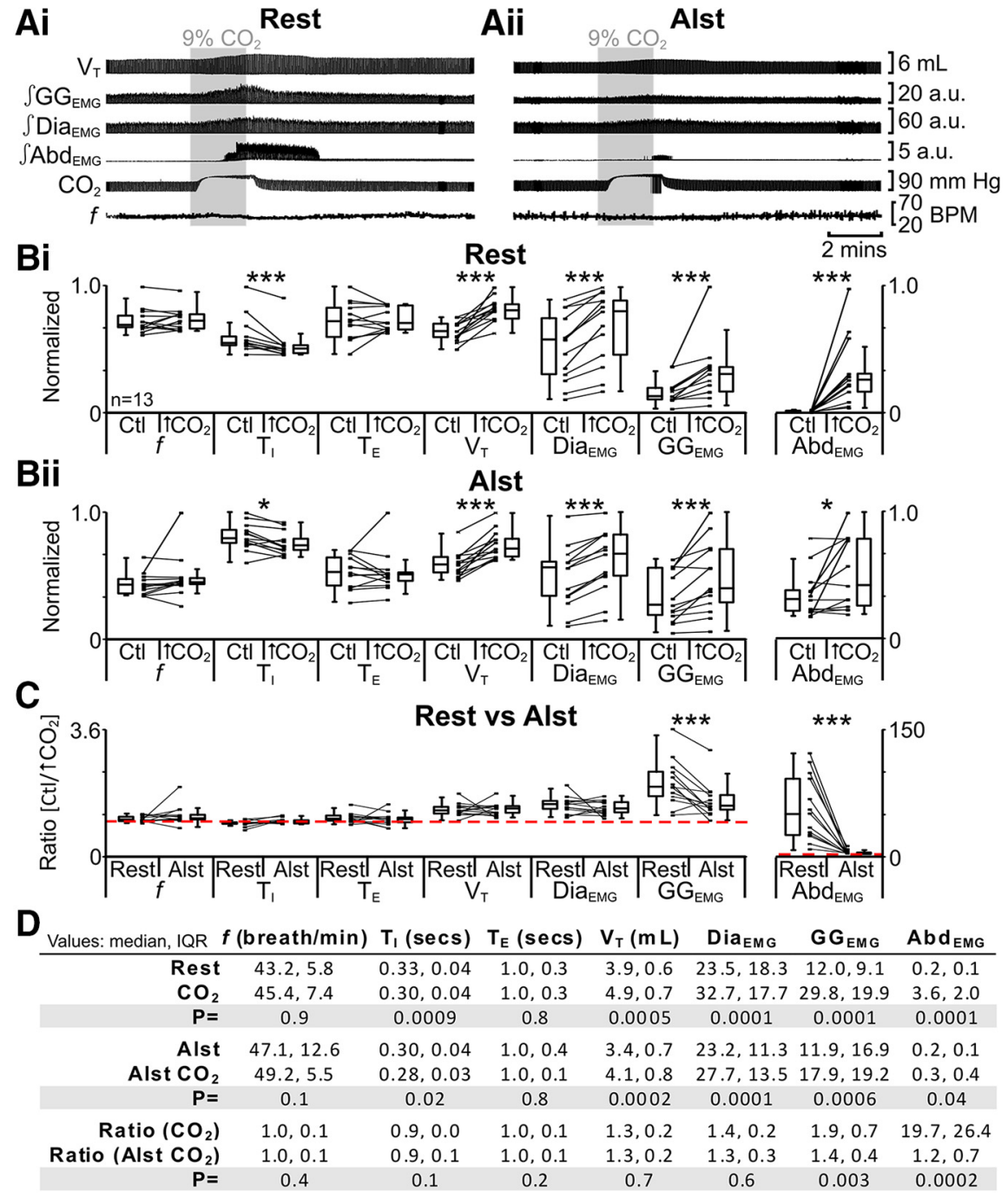

Figure 10. Hyperpolarizing $\mathrm{pF}_{\mathbf{v}}$ neurons reduced effects of hypercapnia $\left(9 \% \mathrm{CO}_{2}\right)$ on $\mathrm{Abd}_{\mathrm{EMG}}$ and $\mathrm{GG}_{\mathrm{EMG}}$. $\boldsymbol{A}$, Integrated traces from a single experiment: shaded area shows period of hypercapnia. $\boldsymbol{A i}$, Rest. $\boldsymbol{A i i}$, After addition of Alst into $\mathrm{pF}_{\mathrm{V}}$ (present for entire trace). $\boldsymbol{B}$, Comparison of respiratory variables before and after hypercapnia in $\mathrm{pF}_{\mathrm{v}}: A l s t R$ rats at rest $(\boldsymbol{B} \boldsymbol{i})$ and in the presence of Alst (Bii). Lines connect data from individual experiments, and box-and-whisker plots show combined data. Data in $\mathbf{B i}$ and $\mathbf{B i}$ are normalized to highest value for that parameter, i.e., $f, T_{I}, T_{E}, V_{T}, G_{E M G}, D_{i a} a_{E M}$, or $A_{b d} d_{E M G}$, regardless of whether it belonged to control or $9 \% \mathrm{CO}_{2}$ group. $C$, Comparison between ratio changes induced by hypercapnia in $\mathrm{pF}_{\mathrm{V}}$ :AlstR rats at rest and in the presence of Alst. Data in Care expressed as ratios of resting values, and red horizontal dashed line represents a ratio of 1.D, Table containing median, IQR, and $p$ values, from data represented in $B .{ }^{*} p<0.05,{ }^{* *} p<0.01,{ }^{* * *} p<0.005$.

increased $\mathrm{T}_{\mathrm{E}}(p=0.008), \mathrm{V}_{\mathrm{T}}(p=0.02), \operatorname{Dia}_{\mathrm{EMG}}(p=0.008)$, and $\mathrm{GG}_{\mathrm{EMG}}(p=0.008)$; and induced expiratory-related $\mathrm{Abd}_{\mathrm{EMG}}$ ( $p=0.008 ; n=7$; data not shown). The same trends $(n=7 ; f: p=$ $0.02 ; \mathrm{T}_{\mathrm{I}}: p=0.04 ; \mathrm{T}_{\mathrm{E}}: p=0.008 ; \mathrm{V}_{\mathrm{T}}: p=0.02 ; \operatorname{Dia}_{\mathrm{EMG}}: p=0.008$; $\mathrm{GG}_{\mathrm{EMG}}: p=0.008$; $\operatorname{Abd}_{\mathrm{EMG}}: p=0.008$; data not shown) were seen in the presence of Alst (Fig. 1v). Importantly, in the presence of Alst following $\mathrm{B}+\mathrm{S}_{\mathrm{pF}}$, the ratio changes $\left[\left(\mathrm{B}+\mathrm{S}_{\mathrm{pF}_{\mathrm{L}}}+\mathrm{Alst}\right) /\right.$ $(\mathrm{Ctl}+\mathrm{Alst})]$ for all measured variables were not significantly different to the ratio changes in the absence of Alst $\left[\mathrm{B}+\mathrm{S}_{\mathrm{pF}_{\mathrm{L}}} / \mathrm{Ctl}\right]$ $\left(n=7 ; f: p=0.5 ; \mathrm{T}_{\mathrm{I}}: p=0.6 ; \mathrm{T}_{\mathrm{E}}: p=0.8 ; \mathrm{V}_{\mathrm{T}}: p=0.8 ; \operatorname{Dia}_{\mathrm{EMG}}: p=\right.$ $0.3 ; \mathrm{GG}_{\mathrm{EMG}}: p=0.6 ; \mathrm{Abd}_{\mathrm{EMG}}: p=0.8$; data not shown). Thus Alst in the absence of AlstRs did not affect the response to $\mathrm{B}+\mathrm{S}_{\mathrm{pF}}$.

Hyperpolarizing $\mathrm{pF}_{\mathrm{V}}$ neurons during hypercapnia attenuates $\mathrm{GG}_{\mathrm{EMG}}$ and $\mathrm{Abd}_{\mathrm{EMG}}$

To assess the role of the $\mathrm{pF}_{\mathrm{V}}$ in chemoreflexes, we first tested the response to hypercapnia. In anesthetized rats at rest transfected with AlstR in the ventral parafacial, i.e., $\mathrm{pF}_{\mathrm{V}}$ :AlstR rats (Fig. 1ii,iii), hypercapnia did not affect $f$; decreased $\mathrm{T}_{\mathrm{I}}$; did not affect $\mathrm{T}_{\mathrm{E}}$; increased $\mathrm{V}_{\mathrm{T}}, \mathrm{Dia}_{\mathrm{EMG}}$, and $\mathrm{GG}_{\mathrm{EMG}}$; and induced expiratory-related $\mathrm{Abd}_{\mathrm{EMG}}$ $(n=13$; Fig. $10 A i, B i, D)$. The same trends $(n=13$; Fig. $10 A i i, B i i, D)$ were seen in the presence of Alst (Fig. 1vi,vii). However, in the presence of Alst during hypercapnia, only the ratio changes [(hypercapnia + Alst $) /(\mathrm{Ctl}+$ Alst $)]$ for inspiratory-related $\mathrm{GG}_{\mathrm{EMG}}$ and expiratory-related $\mathrm{Abd}_{\mathrm{EMG}}$ were significantly closer to 1 than the ratio changes in the absence of Alst [hypercapnia/Ctl] $(n=13$; Fig. $10 C, D)$. Alst in the absence of AlstRs did not affect the response to hypercapnia (see next paragraph). Thus hyperpolarizing $\mathrm{pF}_{\mathrm{V}}$ neurons during hypercapnia decreased both inspiratory-related $\mathrm{GG}_{\mathrm{EMG}}$ and expiratory-related $\mathrm{Abd}_{\mathrm{EMG}}$ activity.

\section{Alst does not affect the response to hypercapnia in the absence of AlstRs} In anesthetized rats at rest with no AlstRs, i.e., $\mathrm{pF}_{\mathrm{L}}: \mathrm{HM}_{4} \mathrm{DR}$ rats (Fig. 1i), hypercapnia did not affect $f(p=0.8)$; decreased $\mathrm{T}_{\mathrm{I}}$ $(p=0.04)$; did not affect $\mathrm{T}_{\mathrm{E}}(p=0.3)$; increased $\mathrm{V}_{\mathrm{T}}(p=0.02), \operatorname{Dia}_{\mathrm{EMG}}(p=$ $0.02)$, and $\mathrm{GG}_{\mathrm{EMG}}(p=0.02)$; and induced expiratory-related $\operatorname{Abd}_{\mathrm{EMG}}(p=$ $0.02 ; n=7$; data not shown). The same trends $\left(n=7 ; f: p=0.9 ; \mathrm{T}_{\mathrm{I}}: p=0.02 ; \mathrm{T}_{\mathrm{E}}\right.$ : $p=0.8 ; \mathrm{V}_{\mathrm{T}}: p=0.02 ; \operatorname{Dia}_{\mathrm{EMG}}: p=0.02$; $\mathrm{GG}_{\mathrm{EMG}}: p=0.02$ Abd $_{\mathrm{EMG}}: p=0.02$; data not shown) were seen in the presence of Alst (Fig. 1v). Importantly, in the presence of Alst during hypercapnia, the ratio changes [(hypercapnia + Alst) $/(\mathrm{Ctl}+$ Alst)] for all measured variables was not significantly different to those in the absence of Alst [hypercapnia/Ctl] $(n=7 ; f$ : $p=0.5 ; \mathrm{T}_{\mathrm{I}}: p=0.2 ; \mathrm{T}_{\mathrm{E}}: p=0.3 ; \mathrm{V}_{\mathrm{T}}: p=$ $0.08 ; \mathrm{Dia}_{\mathrm{EMG}}: p=0.4 \mathrm{GG}_{\mathrm{EMG}}: p=0.5$; $\operatorname{Abd}_{\mathrm{EMG}}: p=0.7$; data not shown). Thus Alst in the absence of AlstR did not affect the response to hypercapnia.

\section{Hyperpolarizing $\mathrm{pF}_{\mathrm{V}}$ neurons during hypoxia attenuates} $\mathrm{GG}_{\mathrm{EMG}}$ and $\mathrm{Abd}_{\mathrm{EMG}}$

Using a similar sequence of protocols, we next tested the effect of hypoxia at rest. In anesthetized rats at rest transfected with AlstR in the ventral parafacial, i.e., $\mathrm{pF}_{\mathrm{V}}$ :AlstR rats (Fig. 1ii,iii) under resting conditions, hypoxia increased $f$; decreased $\mathrm{T}_{\mathrm{I}}$ and $\mathrm{T}_{\mathrm{E}}$; increased $\mathrm{V}_{\mathrm{T}}, \mathrm{Dia}_{\mathrm{EMG}}$, and $\mathrm{GG}_{\mathrm{EMG}}$; and induced expiratory-related $\operatorname{Abd}_{\mathrm{EMG}}(n=13$; Fig. $11 A i, B i, D)$. The same trends $(n=13$; Fig. $11 \mathrm{Aii}, \mathrm{Bii}, \mathrm{D})$ were seen in the presence of Alst (Fig. 1vi,vii). However, in the presence of Alst during hypoxia, only the ratio changes $[($ hypoxia + Alst $) /(\mathrm{Ctl}+$ Alst $)]$ for inspiratory-related $\mathrm{GG}_{\mathrm{EMG}}$ and expiratory-related $\mathrm{Abd}_{\mathrm{EMG}}$ were significantly closer to 1 than the ratio changes in the absence of Alst [hypoxia/Ctl] $(n=13$; Fig. $11 C, D)$. Alst in the absence of AlstRs did not affect the response to hypoxia (see next paragraph). Thus hyperpolar- 
izing $\mathrm{pF}_{\mathrm{V}}$ neurons during hypoxia decreased both inspiratory-related $\mathrm{GG}_{\mathrm{EMG}}$ and expiratory-related $\mathrm{Abd}_{\mathrm{EMG}}$ activity.

Alst does not affect the response to hypoxia in the absence of AlstRs

In anesthetized rats at rest with no AlstRs, i.e., $\mathrm{pF}_{\mathrm{L}}: \mathrm{HM}_{4} \mathrm{DR}$ rats (Fig. 1 i), hypoxia increased $f(p=0.02)$; decreased $\mathrm{T}_{\mathrm{I}}(p=$ $0.02)$ and $\mathrm{T}_{\mathrm{E}}(p=0.02)$; increased $\mathrm{V}_{\mathrm{T}}$ $(p=0.03), \operatorname{Dia}_{\mathrm{EMG}}(p=0.03)$, and $\mathrm{GG}_{\mathrm{EMG}}(p=0.02) ;$ and induced expiratory-related $\mathrm{Abd}_{\mathrm{EMG}}$ activity $(p=$ $0.02 ; n=7$; data not shown). The same trends $\left(n=7 ; f: p=0.02 ; \mathrm{T}_{\mathrm{I}}: p=0.01 ; \mathrm{T}_{\mathrm{E}}\right.$ : $p=0.02 ; \mathrm{V}_{\mathrm{T}}: p=0.02 ; \mathrm{Dia}_{\mathrm{EMG}}: p=0.02$; $\mathrm{GG}_{\mathrm{EMG}}: p=0.008 ; \operatorname{Abd}_{\mathrm{EMG}}: p=0.02$; data not shown) were seen in the presence of Alst (Fig. 1v). Importantly, in the presence of Alst, during hypoxia, the ratio changes [(hypoxia + Alst $) /(\mathrm{Ctl}+$ Alst $)]$ for all measured variables were not significantly different to those in the absence of Alst [hypoxia/Ctl] $\left(n=7 ; f: p=1.0 ; \mathrm{T}_{\mathrm{I}}\right.$ : $p=0.3 ; \mathrm{T}_{\mathrm{E}}: p=1.0 ; \mathrm{V}_{\mathrm{T}}: p=0.8 ; \operatorname{Dia}_{\mathrm{EMG}}$ : $p=0.2 ; \mathrm{GG}_{\mathrm{EMG}}: p=0.2 ; \operatorname{Abd}_{\mathrm{EMG}}: p=0.2$; data not shown). Thus Alst in the absence of AlstR did not affect the response to hypoxia.

\section{AlstR and $\mathrm{HM}_{4} \mathrm{DR}$ are equally effective in our experimental paradigms \\ Differences in the effects of hyperpolarizing $\mathrm{pF}_{\mathrm{V}}$ or $\mathrm{pF}_{\mathrm{L}}$ neurons could be due to the differ- ences in the effects of activating $\mathrm{HM}_{4} \mathrm{DR}$ ver- sus AlstRs, and not a functional distinction between $\mathrm{pF}_{\mathrm{V}}$ and $\mathrm{pF}_{\mathrm{L}}$. To assess this, we trans- fected the $\mathrm{pF}_{\mathrm{V}}$ with $\mathrm{HM}_{4} \mathrm{DRs}$. \\ We first tested the response to hyper- capnia. In anesthetized rats at rest trans- fected with $\mathrm{HM}_{4} \mathrm{DR}$ in the ventral parafacial, i.e., $\mathrm{pF}_{\mathrm{V}}: \mathrm{HM}_{4} \mathrm{DR}$ rats (Fig. 1iv,xii), hypercapnia did not affect $f$; decreased $\mathrm{T}_{\mathrm{I}}$; did not affect $\mathrm{T}_{\mathrm{E}}$; increased $\mathrm{V}_{\mathrm{T}}, \mathrm{Dia}_{\mathrm{EMG}}$, and $\mathrm{GG}_{\mathrm{EMG}}$; and induced expiratory-related $\mathrm{Abd}_{\mathrm{EMG}}(n=13$; Fig.}

$12 A i, B i, D)$. The same trends $(n=13$; Fig. $12 A i i, B i i, D)$ were seen in the presence of CNO (Fig. 1viii). However, in the presence of $\mathrm{CNO}$, during hypercapnia, only the ratio changes [(hypercapnia $+\mathrm{CNO}) /(\mathrm{Ctl}+\mathrm{CNO})]$ for inspiratory-related $\mathrm{GG}_{\mathrm{EMG}}$ and expiratory-related $\mathrm{Abd}_{\mathrm{EMG}}$ were significantly closer to 1 than the ratio changes in the absence of CNO [hypercapnia/Ctl] $(n=13$; Fig. $12 C, D)$. Thus hyperpolarizing $\mathrm{pF}_{\mathrm{V}}: \mathrm{HM}_{4} \mathrm{DR}$ neurons during hypercapnia affected both inspiratory-related $\mathrm{GG}_{\mathrm{EMG}}$ and expiratory-related $\mathrm{Abd}_{\mathrm{EMG}}$. Regardless of whether the $\mathrm{pF}_{\mathrm{V}}$ neurons were hyperpolarized via the activation of AlstRs or $\mathrm{HM}_{4} \mathrm{DRs}$, the ratio changes, i.e., [(hypercapnia + Alst $) /(\mathrm{Ctl}+\mathrm{Alst})]$ vs [(hypercapnia $+\mathrm{CNO}) /(\mathrm{Ctl}+\mathrm{CNO})]$, were similar for inspiratory-related $\mathrm{GG}_{\mathrm{EMG}}\left(n=21 ; \mathrm{pF}_{\mathrm{V}}:\right.$ AlstR: 1.4 IQR $0.4 ; \mathrm{pF}_{\mathrm{V}}: \mathrm{HM}_{4} \mathrm{DR}: 1.6 \mathrm{IQR} 0.7$; Kruskal-Wallis; $p=0.7$; data not shown) and expiratory-related $\operatorname{Abd}_{\mathrm{EMG}}\left(n=21 ; \mathrm{pF}_{\mathrm{V}}\right.$ :AlstR: 1.2 IQR 0.7; $\mathrm{pF}_{\mathrm{V}}: \mathrm{HM}_{4} \mathrm{DR}$ : 1.6 IQR 1.6; Kruskal-Wallis; $p=0.2$; data not shown).
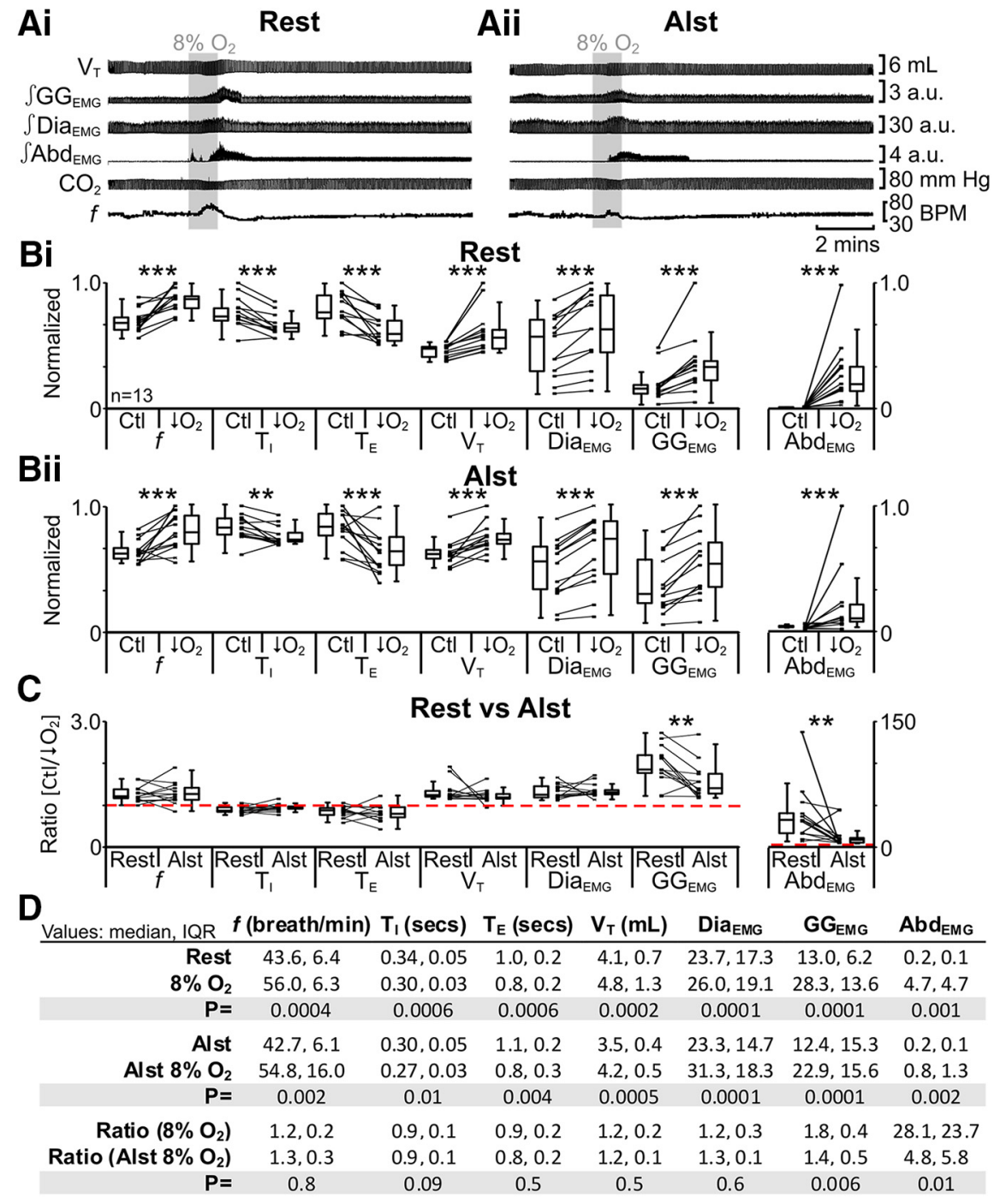

Figure 11. Hyperpolarizing $\mathrm{pF}_{\mathrm{V}}$ neurons reduced effects of hypoxia $\left(8 \% \mathrm{O}_{2}\right)$ on $\mathrm{Abd}_{\mathrm{EMG}}$ and $\mathrm{GG}_{\mathrm{EMG}} \cdot \boldsymbol{A}$, Integrated traces from a single experiment: shaded area shows period of hypoxia. $\boldsymbol{A} \boldsymbol{i}$, Rest. Aii, After addition of Alst into $\mathrm{pF}_{\mathrm{v}}$ (present for entire trace). $\boldsymbol{B}$, Comparison of respiratory variables before and after hypoxia in $\mathrm{pF}_{\mathrm{v}}$ :AlstR rats at rest $(\boldsymbol{B i})$ and in the presence of Alst (Bii). Lines group. $C$, Comparison between ratio changes induced by hypoxia in $\mathrm{pF}_{\mathrm{v}}$ :AlstR rats at rest and in the presence of Alst. Data in $\mathrm{C}$ are expressed as ratios of resting values, and red horizontal dashed line represents a ratio of 1.D, Table containing median, IQR, and $p$ values, from data represented in $\boldsymbol{B} .{ }^{*} p<0.05,{ }^{* *} p<0.01,{ }^{* * *} p<0.005$.

Using a similar sequence of protocols, we next tested the effect of hypoxia. In anesthetized rats at rest transfected with $\mathrm{HM}_{4} \mathrm{DR}$ in the ventral parafacial, i.e., $\mathrm{pF}_{\mathrm{V}}: \mathrm{HM}_{4} \mathrm{DR}$ rats (Fig. 1 iv, xii), hypoxia increased $f$; decreased $\mathrm{T}_{\mathrm{I}}$ and $\mathrm{T}_{\mathrm{E}}$; increased $\mathrm{V}_{\mathrm{T}}, \mathrm{Dia}_{\mathrm{EMG}}$, and $\mathrm{GG}_{\mathrm{EMG}}$; and induced expiratory-related $\operatorname{Abd}_{\mathrm{EMG}}(n=13$; Fig. 13Ai,Bi,D). The same trends $(n=13$; Fig. $13 A i i, B i i, D)$ were seen in the presence of $\mathrm{CNO}$ (Fig. 1 viii). However, in the presence of $\mathrm{CNO}$, during hypoxia, only the ratio changes [(hypoxia $+\mathrm{CNO}) /(\mathrm{Ctl}+\mathrm{CNO})]$ for inspiratory-related $\mathrm{GG}_{\mathrm{EMG}}$ and expiratory-related $\mathrm{Abd}_{\mathrm{EMG}}$ were significantly closer to 1 than the ratio changes in the absence of $\mathrm{CNO}$ [hypoxia/Ctl] ( $n=13$; Fig. 13C,D). Thus similar to hypercapnia, hyperpolarizing $\mathrm{pF}_{\mathrm{V}}: \mathrm{HM}_{4} \mathrm{DR}$ neurons with $\mathrm{CNO}$ attenuated the effects of hypoxia on active expiration as well as inspiration. Regardless of whether $\mathrm{pF}_{\mathrm{V}}$ neurons were hyperpolarized via the activation of AlstRs or $\mathrm{HM}_{4} \mathrm{DRs}$, the ratio changes, i.e., [(hypoxia $\left.+\mathrm{Alst}\right) /(\mathrm{Ctl}+$ Alst $)]$ vs [(hypoxia $+\mathrm{CNO}) /(\mathrm{Ctl}+\mathrm{CNO})]$, were similar for inspiratory-related $\mathrm{GG}_{\mathrm{EMG}}\left(n=21 ; \mathrm{pF}_{\mathrm{V}}\right.$ :AlstR: $1.3 \mathrm{IQR} 0.5 ; \mathrm{pF}_{\mathrm{V}}$ : 


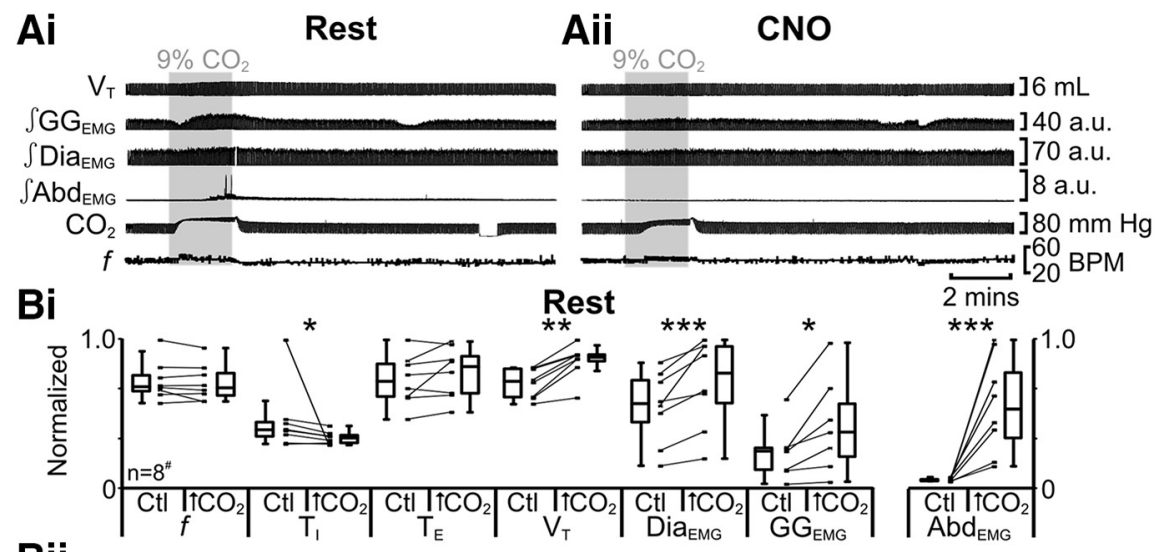

$\mathrm{Bii}$

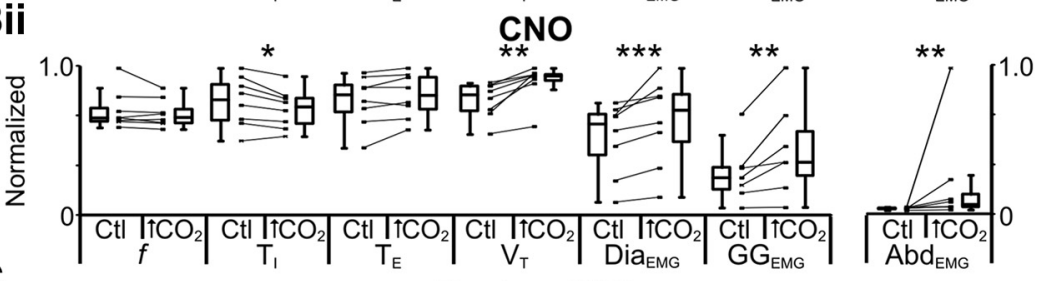

C

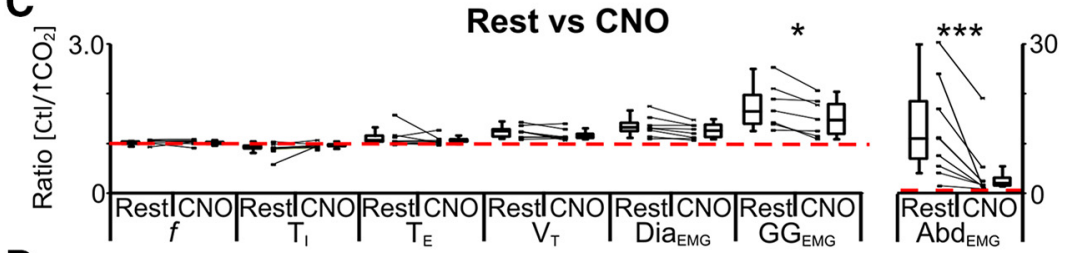

D

\begin{tabular}{|c|c|c|c|c|c|c|c|}
\hline Values: median, IQR & eath/min) & $T_{1}$ (secs) & $T_{E}$ (secs) & $\mathrm{V}_{\mathrm{T}}(\mathrm{mL})$ & $\mathrm{Dia}_{\mathrm{EMG}}$ & $\mathbf{G G}_{\mathrm{EMG}}$ & $\mathrm{Abd}_{\mathrm{EMG}}$ \\
\hline Rest & $41.0,6.6$ & $0.32,0.08$ & $1.1,0.3$ & $4.3,1.2$ & $29.4,15.1$ & $12.5,7.1$ & $0.2,0.0$ \\
\hline $\mathrm{CO}_{2}$ & $40.7,9.3$ & $0.27,0.04$ & $1.2,0.4$ & $5.3,0.3$ & $40.2,20.2$ & $18.7,17.3$ & $2.0,1.7$ \\
\hline$P=$ & 0.8 & 0.03 & 0.1 & 0.008 & 0.004 & 0.02 & 0.008 \\
\hline CNO & 40.5 .5 .5 & 0.29 .0 .09 & 1.2. 0.3 & 4.3. 0.9 & 36.4. 16.0 & 11.4 .6 .4 & 0.2 .0 .0 \\
\hline $\mathrm{CNO} \mathrm{CO}_{2}$ & 40.9 .5 .8 & 0.27 .0 .06 & 1.2. 0.3 & 5.0.0.2 & 41.7. 18.5 & 16.0. 13.1 & $0.3 \cdot 0.3$ \\
\hline$P=$ & 0.2 & 0.03 & 0.07 & 0.008 & 0.004 & 0.008 & 0.01 \\
\hline Ratio $\left(\mathrm{CO}_{2}\right)$ & $1.0,0.0$ & $0.9,0.1$ & $1.0,0.1$ & $1.2,0.2$ & $1.3,0.2$ & $1.6,0.6$ & $10.7,11.8$ \\
\hline Ratio $\left(\mathrm{CNO} \mathrm{CO}_{2}\right)$ & 1.0 .0 .0 & $0.9 \cdot 0.0$ & 1.0. 0.1 & 1.1. 0.1 & 1.2. 0.3 & 1.5. 0.6 & 1.6.1.5 \\
\hline $\mathrm{P}=$ & 0.6 & 0.055 & 0.6 & 0.3 & 0.055 & 0.02 & 0.008 \\
\hline
\end{tabular}

Figure 12. Hyperpolarizing $\mathrm{pF}_{\mathrm{V}}$ neurons during hypercapnia $\left(9 \% \mathrm{CO}_{2}\right)$ with $\mathrm{HM}_{4} \mathrm{DR}$ only affects $\mathrm{GG}_{\mathrm{EMG}}$ and $\mathrm{Abd}_{\mathrm{EMG}}$. $A$, Integrated traces from a single experiment: shaded area shows period of hypercapnia. Ai, Rest. Aii, During application of CNO to medullary surface (present for entire trace). $\boldsymbol{B}$, Comparison of respiratory variables before and after hypercapnia in $\mathrm{pF}_{\mathrm{V}}: \mathrm{HM}_{4} \mathrm{DR}$ rats at rest (Bi) and in the presence of $\mathrm{CNO}$ (Bii). Lines connect data from individual experiments, and box-and-whisker plots show combined data. Data in $\boldsymbol{B i}$ and $\boldsymbol{B i i}$ are normalized to highest value for that parameter, i.e., $f_{,} \mathrm{T}_{\mathrm{I}} \mathrm{T}_{\mathrm{E}^{\prime}}, \mathrm{V}_{\mathrm{T}}, \mathrm{GG}_{\mathrm{EMG}}, \operatorname{Dia}_{\mathrm{EMG}}$ or $\mathrm{Abd}_{\mathrm{EMG}}$ regardless of whether it belonged to control or $9 \% \mathrm{CO}_{2}$ group. $\mathrm{C}$, Comparison between ratio changes induced by hypercapnia in $\mathrm{PF}_{\mathrm{v}}: \mathrm{HM}_{4} \mathrm{DR}$ rats at rest and in presence of $\mathrm{CNO}$. Data in $C$ are expressed as ratios of resting values, and red horizontal dashed line represents a ratio of $1 . \boldsymbol{D}$, Table containing median, IQR, and $p$ values, from data represented in $\boldsymbol{B} .{ }^{*} p<0.05$, ${ }^{* *} p<0.01,{ }^{* * *} p<$ 0.005. ${ }^{\#} n=7$ for $\mathrm{GG}_{\mathrm{EMG}}$.

$\mathrm{HM}_{4}$ DR: 1.6 IQR 0.5; Kruskal-Wallis; $p=0.5$; data not shown) and expiratory-related $\mathrm{Abd}_{\mathrm{EMG}}\left(n=21 ; \mathrm{pF}_{\mathrm{V}}\right.$ :AlstR: $4.8 \mathrm{IQR} 5.8 ; \mathrm{pF}_{\mathrm{V}}$ : $\mathrm{HM}_{4}$ DR: 9.2 IQR 8.2; Kruskal-Wallis; $p=0.2$; data not shown). Thus the disparities between the $\mathrm{pF}_{\mathrm{L}}$ and $\mathrm{pF}_{\mathrm{V}}$ in terms of the response to hypercapnia and hypoxia are due to functional differences between the $\mathrm{pF}_{\mathrm{V}}$ and $\mathrm{pF}_{\mathrm{L}}$.

\section{Discussion}

We investigated the respective contributions of two adjacent parafacial regions in controlling breathing pattern. To do this we combined two recently developed technologies for hyperpolarizing neurons, i.e., transfection of neurons with AlstRs or $\mathrm{HM}_{4} \mathrm{DRs}$ followed by exogenous application of their ligand (Alst or CNO), to illuminate their differences in function. By making these perturbations in the same rat we could discriminate these differ- ences. Although we focus on breathing, this approach can be used in any region of the brain to parse out differences in function among neighboring subpopulations, and where distinguishing genetic markers can be exploited, one could discriminate between overlapping populations.

Breathing in mammals is a complex behavior with critical sites in the brainstem for rhythm and pattern generation and for sensory processing. An emerging picture is that distinct regions have specific functional roles (Feldman et al., 2013), such as in $\mathrm{CO}_{2}$-chemoreception (Guyenet et al., 2010; Hodges and Richerson, 2010; Huckstepp and Dale, 2011; Nattie, 2011), or in generation of expiratory (Onimaru and Homma, 2003; Janczewski and Feldman, 2006; Pagliardini et al., 2011) or inspiratory (Smith et al., 1991; Tan et al., 2008) rhythm. Appropriate parcellation of distinct respiratory functions to definable brainstem regions is essential for understanding neural control of breathing. Since the identification of the parafacial RTN (Smith et al., 1989; Ellenberger and Feldman, 1990; Li et al., 1999; Mulkey et al., 2004), increasing attention has been focused on understanding its role and, as more data became available (Onimaru and Homma, 2003; Janczewski and Feldman, 2006; Feldman et al., 2009; Pagliardini et al., 2011; Tupal et al., 2014), e.g., the role of other parafacial regions. In adult rats, we found that two anatomically separate parafacial regions, the $\mathrm{pF}_{\mathrm{V}}$ and $\mathrm{pF}_{\mathrm{L}}$, perform very distinct roles in control of breathing, with an overlapping role in central chemoreception.

\section{$\mathrm{pF}_{\mathrm{V}}$ and $\mathrm{pF}_{\mathrm{L}}$ have different active states at rest}

At rest the lack of significant expiratory pumping by abdominal muscles (Iizuka and Fregosi, 2007) can be transformed into active expiration by disinhibition or photoactivation of the presumptive $\mathrm{pF}_{\mathrm{L}}$ (Pagliardini et al., 2011). This suggests that the $\mathrm{pF}_{\mathrm{L}}$ is silent at rest due to tonic suppression by inhibitory neurons, and that once disinhibited and/or excited, the $\mathrm{pF}_{\mathrm{L}}$ drives active expiration (Pagliardini et al., 2011). We predicted that hyperpolarizing $\mathrm{pF}_{\mathrm{L}}: \mathrm{HM}_{4} \mathrm{DR}$ neurons should not alter basal ventilation, and that was the case (Fig. 4).

Disinhibition in the $\mathrm{pF}_{\mathrm{L}}$, i.e., $\mathrm{B}+\mathrm{S}_{\mathrm{pF}}$, produces expiratoryrelated $\mathrm{Abd}_{\mathrm{EMG}}$ activity (Pagliardini et al., 2011), a reduction in $f$ with a concomitant increase in $\mathrm{V}_{\mathrm{T}}$, and an increase in inspiratoryrelated $\mathrm{Dia}_{\mathrm{EMG}}$ and $\mathrm{GG}_{\mathrm{EMG}}$. In $\mathrm{pF}_{\mathrm{L}}: \mathrm{HM}_{4} \mathrm{DR}$-transfected rats, these effects were significantly reduced following application of CNO (Fig. 5). That CNO did not completely abolish the effects of $\mathrm{B}+\mathrm{S}_{\mathrm{pF}}$ is likely due to incomplete transfection of $\mathrm{pF}_{\mathrm{L}}$ neurons ( 76\%; Fig. 2) in the effective $\mathrm{B}+\mathrm{S}_{\mathrm{pF}_{\mathrm{L}}}$ injection site and/or $\mathrm{B}+$ $\mathrm{S}_{\mathrm{pF}}$ produced sufficient disinhibitory depolarization to over- 
come the hyperpolarizing effects of $\mathrm{CNO}$ on $\mathrm{HM}_{4} \mathrm{DR}$-transfected neurons. We conclude that the $\mathrm{pF}_{\mathrm{L}}$ is silent at rest due, at least in part, to postsynaptic inhibition mediated by $\mathrm{GABA}_{\mathrm{A}}$ ergic and/or glycinergic receptors, but once sufficiently excited, triggers active expiration; this is consistent with our hypothesis that the $\mathrm{pF}_{\mathrm{L}}$ is a conditional expiratory oscillator (Fig. 14; Mellen et al., 2003; Janczewski and Feldman, 2006; Pagliardini et al., 2011).

The area ventral to the facial nucleus is generally accepted to process and integrate multiple sensory inputs related to ventilation and provide a facilitatory drive to breathe (Nattie, 2000; Li et al., 2006; Moreira et al., 2007a; Mulkey et al., 2007). Consistent with previous results (Nattie and Li, 2002; Marina et al., 2010), we found that hyperpolarizing $\mathrm{pF}_{\mathrm{V}}$ :AlstR neurons reduced basal ventilation, via a reduction in $\mathrm{V}_{\mathrm{T}}$ due, at least in part, to attenuated Dia ${ }_{\mathrm{EMG}}$ activity with no change in $f$ (Fig. 8). We conclude that at rest the $\mathrm{pF}_{\mathrm{V}}$ provides an excitatory drive to breathe (Fig. 14).

$\mathrm{pF}_{\mathrm{V}}$ and $\mathrm{pF}_{\mathrm{L}}$ have different roles in the response to both hypoxia

and hypercapnia

In vagotomized urethane-anesthetized rats at rest, both the $\mathrm{pF}_{\mathrm{V}}$ and $\mathrm{pF}_{\mathrm{L}}$ are involved in responses to hypoxia and hypercapnia. The $\mathrm{pF}_{\mathrm{V}}$ and $\mathrm{pF}_{\mathrm{L}}$ were distinguished by their particular roles in these responses. Hyperpolarizing $\mathrm{pF}_{\mathrm{L}}$ neurons only attenuated hypercapniainduced (Fig. 6) and hypoxia-induced (Fig. 7) expiratory-related $\mathrm{Abd}_{\mathrm{EMG}}$, suggesting that this change is not related to the modality of the perturbation, but was specific to the initiation and maintenance of active expiration. Hyperpolarizing $\mathrm{pF}_{\mathrm{V}}$ neurons attenuated increases in both hypercapniainduced (Figs. 10, 12) and hypoxiainduced (Figs. 11, 13) expiratory-related $\mathrm{Abd}_{\mathrm{EMG}}$ and inspiratory-related $\mathrm{GG}_{\mathrm{EMG}}$, suggesting that these changes are not related to the modality of the perturbation, but were specific to the loss of facilitatory drive affecting respiratory muscle activity. Thus when ventilatory demand increases due to changes in blood gases, the $\mathrm{pF}_{\mathrm{L}}$ drives active expiration and the $\mathrm{pF}_{\mathrm{V}}$ decreases airway resistance during inspiration along with a concomitant facilitatory drive that increases expiratory-related $\mathrm{Abd}_{\mathrm{EMG}}$ activity (Fig. 14).

Further evidence the $\mathrm{pF}_{\mathrm{L}}$ is a conditional expiratory oscillator The $\mathrm{pF}_{\mathrm{V}}$ contains glutamatergic neurons (Nattie and Li, 2002; Mulkey et al., 2004; Stornetta et al., 2006), lacks glycinergic neurons (Tanaka et al., 2003; Fortuna et al., 2008; Abbott et al., 2009), and is almost completely devoid of GABAergic neurons (Ellenberger, 1999; Stornetta and Guyenet, 1999; Tanaka et al., 2003). The $\mathrm{pF}_{\mathrm{L}}$ also contains glutamatergic neurons (Onimaru et al., 2008) and lacks inhibitory neurons (Ellenberger, 1999; Stornetta and Guyenet, 1999; Tanaka et al., 2003). Thus for this discussion we consider neurons in these parafacial regions to be exclusively excitatory.

Disinhibition of the $\mathrm{pF}_{\mathrm{L}}$ (with $\mathrm{B}+\mathrm{S}_{\mathrm{pF}_{\mathrm{L}}}$ ) reduces $f$ (Fig. 5), either directly through activation of preBötC inhibitory neurons or indirectly through activation of BötC inhibitory neurons (Fig. 14). That activation of the $\mathrm{pF}_{\mathrm{L}}$ also led to expiratoryrelated activity on both the $\mathrm{Abd}_{\mathrm{EMG}}$ and $\mathrm{GG}_{\mathrm{EMG}}$ (Fig. 5) suggests that it projects, directly or indirectly, to premotor neurons controlling the abdominal muscles (Janczewski et al., 2002) and the tongue (Fig. 14). Finally, hyperpolarizing $\mathrm{pF}_{\mathrm{L}}$ neurons following hypoxia or hypercapnia only reduced expiratory activity, but did not affect any inspiratory parameters (Figs. 6, 7). Collectively these data are consistent with our hypothesis that the $\mathrm{pF}_{\mathrm{L}}$ gates active expiration, most likely as a conditional expiratory oscillator (Pagliardini et al., 2011). 


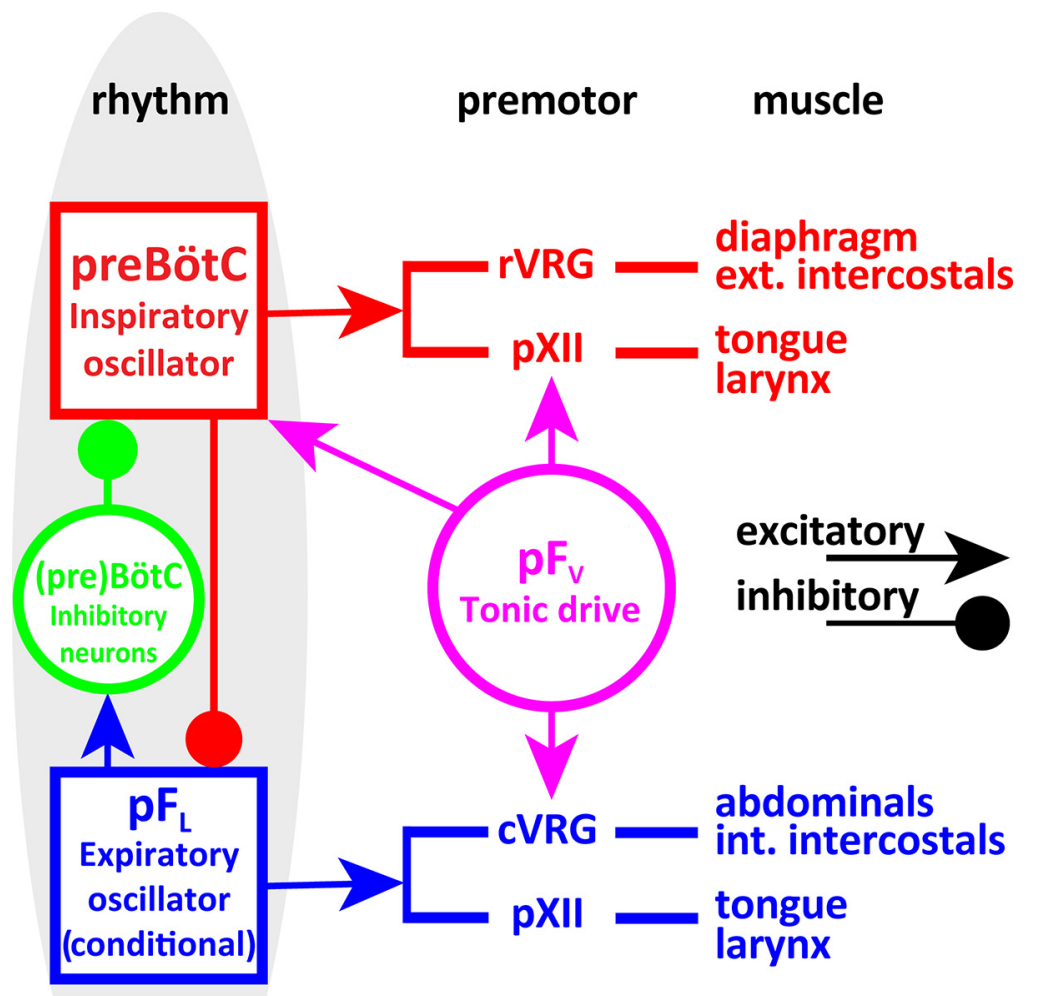

Figure 14. Schematic of minimal respiratory central pattern generator, which at its core consists of three essential components: (1) an inspiratory oscillator in preBötC that drives inspiration by exciting inspiratory premotor neuronal populations, e.g., rVRG and parahypoglossal region ( $\mathrm{pXII}$ ), and inhibits $\mathrm{pF}_{\mathrm{L}}$; (2) a (conditional) expiratory oscillator in $\mathrm{pF}_{\mathrm{L}}$ that gates and drives expiration by exciting expiratory premotor neuronal populations, i.e., cVRG (Janczewski et al., 2002) and pXII, and assures alteration of phases by exciting neurons that inhibit preBötC, e.g., inhibitory neurons in either the preBötC or BötC; and (3) a source of tonic drive in $\mathrm{pF}_{\mathrm{V}}$ that is responsive to $\mathrm{CO}_{2} / \mathrm{pH}$ and integrates other sensory afferents affecting respiratory drive, via excitatory connections to preBötC, BötC, and respiratory premotor neurons, e.g., rVRG, cVRG, and $\mathrm{pXII}$.

$\mathrm{pF}_{\mathrm{V}}$ provides expiratory drive to breathe

Hyperpolarizing either $\mathrm{pF}_{\mathrm{V}}$ or $\mathrm{pF}_{\mathrm{L}}$ neurons attenuated expiratoryrelated $\mathrm{Abd}_{\mathrm{EMG}}$, suggesting either a direct interaction between these nuclei or a downstream convergence of their projections onto abdominal (pre)motoneurons (Janczewski et al., 2002). Due to the apparent lack of inhibitory neurons in the $\mathrm{pF}_{\mathrm{L}}$ and $\mathrm{pF}_{\mathrm{V}}$ (see above), if $\mathrm{pF}_{\mathrm{V}}$ neurons project to the $\mathrm{pF}_{\mathrm{L}}$, hyperpolarizing $\mathrm{pF}_{\mathrm{V}}$ neurons should attenuate all $\mathrm{B}+\mathrm{S}_{\mathrm{pF}_{\mathrm{L}}}$-induced changes in respiration; yet, hyperpolarizing $\mathrm{pF}_{\mathrm{V}}$ neurons only reduced $\mathrm{B}+\mathrm{S}_{\mathrm{pF}_{\mathrm{L}}}$ induced expiratory-related $\mathrm{Abd}_{\mathrm{EMG}}$ but not $f, \mathrm{~T}_{\mathrm{I}}, \mathrm{T}_{\mathrm{E}}, \mathrm{V}_{\mathrm{T}}, \mathrm{GG}_{\mathrm{EMG}}$, or $\mathrm{Dia}_{\mathrm{EMG}}$ (Fig. 9), supporting the idea that the $\mathrm{pF}_{\mathrm{V}}$ modulates expiratory-related abdominal activity at the (pre)motoneuronal level, e.g., expiratory bulbospinal neurons (Janczewski et al., 2002). Importantly, the $\mathrm{pF}_{\mathrm{V}}$ projects directly (Núñez-Abades et al., 1993; Gerrits and Holstege, 1996; Rosin et al., 2006) and indirectly, via the BötC and the parabrachial/Kölliker-fuse nuclei (Núñez-Abades et al., 1993; Rosin et al., 2006), to the caudal ventral respiratory group (cVRG; Fig. 14), which contains bulbospinal neurons projecting to spinal interneurons that in turn project to abdominal motoneurons (Iscoe, 1998; Cinelli et al., 2012), providing a pathway by which the $\mathrm{pF}_{\mathrm{V}}$ can influence expiratory-related $\mathrm{Abd}_{\mathrm{EMG}}$ activity (Fig. 14).

\section{$\mathrm{pF}_{\mathrm{V}}$ provides inspiratory drive}

Interestingly, hyperpolarizing $\mathrm{pF}_{\mathrm{V}}$ neurons had differential effects on the amplitude of inspiratory-related $\mathrm{GG}_{\mathrm{EMG}}$ and Dia $_{\text {EMG }}$ activities, dependent on respiratory drive, i.e., hyperpolarizing $\mathrm{pF}_{\mathrm{V}}$ neurons at rest attenuated $\mathrm{Dia}_{\mathrm{EMG}}$ (Fig. 8), whereas hyperpolarizing $\mathrm{pF}_{\mathrm{V}}$ neurons during hypoxia or hypercapnia reduced $\mathrm{GG}_{\mathrm{EMG}}$ (Figs. 9-12). This suggests that $\mathrm{pF}_{\mathrm{V}}$ neurons that drive the diaphragm are active at rest, but that no additional $\mathrm{pF}_{\mathrm{V}}$ neurons are recruited to drive the diaphragm during active expiration as elicited here. Conversely, neurons that drive the genioglossus are silent at rest but are recruited during active expiration. Thus different $\mathrm{pF}_{\mathrm{V}}$ populations may separately innervate hypoglossal and phrenic premotoneurons. The $\mathrm{pF}_{\mathrm{V}}$ (Rosin et al., 2006) and preBötC (Tan et al., 2010) both innervate a parahypoglossal region (pXII) that is most likely the premotor relay for inspiratory drive to the XII nucleus (Chamberlin et al., 2007). This provides a neural pathway by which the $\mathrm{pF}_{\mathrm{V}}$ may alter the amplitude of $\mathrm{GG}_{\mathrm{EMG}}$ independent of the actions of the preBötC (Fig. 14). Similarly, both the $\mathrm{pF}_{\mathrm{V}}$ (Núñez-Abades et al., 1993; Rosin et al., 2006) and preBötC (Tan et al., 2010) project to the rostral VRG (rVRG), the premotor bulbospinal relay for inspiratory drive to the phrenic nucleus (Portillo and Núñez-Abades, 1992). This provides a neural pathway by which the $\mathrm{pF}_{\mathrm{V}}$ can affect $\mathrm{Dia}_{\mathrm{EMG}}$ independent of the actions of the preBötC (Fig. 14). Therefore we propose that the $\mathrm{pF}_{\mathrm{V}}$ can influence inspiratory-related $\mathrm{Dia}_{\mathrm{EMG}}$ and $\mathrm{GG}_{\mathrm{EMG}}$ activity at the premotoneuronal level, i.e., pXII and rVRG, in addition to any effects mediated by projections to the preBötC (Smith et al., 1989; Ellenberger and Feldman, 1990; Rosin et al., 2006; Abbott et al., 2011; Takakura et al., 2014; Fig. 14).

\section{Summary}

$\mathrm{pF}_{\mathrm{L}}$ neurons have characteristics consistent with their acting as an expiratory oscillator. At rest, in the absence of active expiration (Sherrey et al., 1988; Iizuka and Fregosi, 2007; Marina et al., 2010; Pagliardini et al., 2011), the activity of $\mathrm{pF}_{\mathrm{L}}$ neurons is not expiratory modulated (Pagliardini et al., 2011); when disinhibited, or excited, active expiration is induced and many $\mathrm{pF}_{\mathrm{L}}$ neurons become expiratory modulated (Pagliardini et al., 2011). Consistent with these observations, hyperpolarizing $\mathrm{pF}_{\mathrm{L}}$ neurons affects expiratory-related activity, but not inspiratory-related activity. $\mathrm{pF}_{\mathrm{V}}$ neurons are different. They are active at rest (Mulkey et al., 2004; Moreira et al., 2007b; Stornetta et al., 2009), where they provide excitatory input to the phrenic nerve (Marina et al., 2010) that affects $\mathrm{V}_{\mathrm{T}}$ (Nattie and Li, 2002; Li et al., 2006). Consistent with this observation is that hyperpolarizing $\mathrm{pF}_{\mathrm{V}}$ neurons reduced Dia ${ }_{\mathrm{EMG}}$ amplitude; excitation of $\mathrm{pF}_{\mathrm{V}}$ neurons sufficient to increase inspiratory activity does not induce active expiration 
(Pagliardini et al., 2011, their Fig. 5). When the drive to breathe increases, i.e., during hypoxia and hypercapnia, hyperpolarizing $\mathrm{pF}_{\mathrm{V}}$ neurons affect both inspiratory-related $\mathrm{GG}_{\mathrm{EMG}}$ and expiratory-related $\mathrm{Abd}_{\mathrm{EMG}}$ amplitude. Hyperpolarizing $\mathrm{pF}_{\mathrm{V}}$ neurons did not affect $f$ under any state tested, similar to previous reports involving silencing, or destruction, of presumptive $\mathrm{pF}_{\mathrm{V}}$ neurons (Nattie and Li, 2002; Marina et al., 2010). Thus, the $\mathrm{pF}_{\mathrm{V}}$ appears to provide a generic facilitatory drive to respiratory-related (pre)motoneurons that does not affect frequency.

In conclusion, by differentially decreasing the excitability of neighboring parafacial regions, we identify two distinct functional parafacial regions: the $\mathrm{pF}_{\mathrm{L}}$ is a conditional expiratory oscillator, and the $\mathrm{pF}_{\mathrm{V}}$ provides a generic facilitatory drive to respiration. We postulate that central pattern generation for breathing has (at least) three essential functional components associated with specific sites in the brainstem: (1) an inspiratory oscillator in the preBötC, (2) a (conditional) expiratory oscillator in the $\mathrm{pF}_{\mathrm{L}}$, and (3) a source of respiratory drive related to chemosensory and likely descending inputs (such as related to exercise) in the $\mathrm{pF}_{\mathrm{V}}$ (Fig. 14).

\section{Notes}

Supplemental material for this article is available at http:/feldmanlab. neurobio.ucla.edu. Supplemental information contains figures and legends for control experiments involving $\mathrm{CNO}$ and Alst. This material has not been peer reviewed.

\section{References}

Abbott SB, Stornetta RL, Socolovsky CS, West GH, Guyenet PG (2009) Photostimulation of channelrhodopsin-2 expressing ventrolateral medullary neurons increases sympathetic nerve activity and blood pressure in rats. J Physiol 587:5613-5631. CrossRef Medline

Abbott SB, Stornetta RL, Coates MB, Guyenet PG (2011) Phox2bexpressing neurons of the parafacial region regulate breathing rate, inspiration, and expiration in conscious rats. J Neurosci 31:16410-16422. CrossRef Medline

Birgül N, Weise C, Kreienkamp HJ, Richter D (1999) Reverse physiology in drosophila: identification of a novel allatostatin-like neuropeptide and its cognate receptor structurally related to the mammalian somatostatin/ galanin/opioid receptor family. EMBO J 18:5892-5900. CrossRef Medline

Callaway EM (2005) A molecular and genetic arsenal for systems neuroscience. Trends Neurosci 28:196-201. CrossRef Medline

Chamberlin NL, Eikermann M, Fassbender P, White DP, Malhotra A (2007) Genioglossus premotoneurons and the negative pressure reflex in rats. J Physiol 579:515-526. CrossRef Medline

Cinelli E, Bongianni F, Pantaleo T, Mutolo D (2012) Modulation of the cough reflex by $\mathrm{GABA}_{\mathrm{A}}$ receptors in the caudal ventral respiratory group of the rabbit. Front Physiol 3:403. CrossRef Medline

Ellenberger HH (1999) Distribution of bulbospinal $\gamma$-aminobutyric acidsynthesizing neurons of the ventral respiratory group of the rat. J Comp Neurol 411:130-144. CrossRef Medline

Ellenberger HH, Feldman JL (1990) Brainstem connections of the rostral ventral respiratory group of the rat. Brain Res 513:35-42. CrossRef Medline

Feldman JL, Kam K, Janczewski WA (2009) Practice makes perfect, even for breathing. Nat Neurosci 12:961-963. CrossRef Medline

Feldman JL, Del Negro CA, Gray PA (2013) Understanding the rhythm of breathing: so near, yet so far. Annu Rev Physiol 75:423-452. CrossRef Medline

Fortuna MG, West GH, Stornetta RL, Guyenet PG (2008) Bötzinger expiratory-augmenting neurons and the parafacial respiratory group. J Neurosci 28:2506-2515. CrossRef Medline

Gerrits PO, Holstege G (1996) Pontine and medullary projections to the nucleus retroambiguus: a wheat germ agglutinin-horseradish peroxidase and autoradiographic tracing study in the cat. J Comp Neurol 373:173185. CrossRef Medline

Guyenet PG, Stornetta RL, Bayliss DA, Mulkey DK (2005) Retrotrapezoid nucleus: a litmus test for the identification of central chemoreceptors. Exp Physiol 90:247-257. CrossRef Medline

Guyenet PG, Stornetta RL, Bayliss DA (2010) Central respiratory chemoreception. J Comp Neurol 518:3883-3906. CrossRef Medline

Hodges MR, Richerson GB (2010) Medullary serotonin neurons and their roles in central respiratory chemoreception. Respir Physiol Neurobiol 173:256-263. CrossRef Medline

Huckstepp RT, Dale N (2011) Redefining the components of central $\mathrm{CO}_{2}$ chemosensitivity-towards a better understanding of mechanism. J Physiol 589:5561-5579. Medline

Iizuka M, Fregosi RF (2007) Influence of hypercapnic acidosis and hypoxia on abdominal expiratory nerve activity in the rat. Respir Physiol Neurobiol 157:196-205. CrossRef Medline

Iscoe S (1998) Control of abdominal muscles. Prog Neurobiol 56:433-506. CrossRef Medline

Janczewski WA, Feldman JL (2006) Distinct rhythm generators for inspiration and expiration in the juvenile rat. J Physiol 570:407-420. Medline

Janczewski WA, Onimaru H, Homma I, Feldman JL (2002) Opioidresistant respiratory pathway from the preinspiratory neurones to abdominal muscles: in vivo and in vitro study in the newborn rat. J Physiol 545:1017-1026. CrossRef Medline

Li A, Randall M, Nattie EE (1999) $\mathrm{CO}_{2}$ microdialysis in retrotrapezoid nucleus of the rat increases breathing in wakefulness but not in sleep. J Appl Physiol 87:910-919. Medline

Li A, Zhou S, Nattie E (2006) Simultaneous inhibition of caudal medullary raphe and retrotrapezoid nucleus decreases breathing and the $\mathrm{CO}_{2}$ response in conscious rats. J Physiol 577:307-318. CrossRef Medline

Luo L, Callaway EM, Svoboda K (2008) Genetic dissection of neural circuits. Neuron 57:634-660. CrossRef Medline

Marina N, Abdala AP, Trapp S, Li A, Nattie EE, Hewinson J, Smith JC, Paton JF, Gourine AV (2010) Essential role of Phox2b-expressing ventrolateral brainstem neurons in the chemosensory control of inspiration and expiration. J Neurosci 30:12466-12473. CrossRef Medline

Mellen NM, Janczewski WA, Bocchiaro CM, Feldman JL (2003) Opioidinduced quantal slowing reveals dual networks for respiratory rhythm generation. Neuron 37:821-826. CrossRef Medline

Moreira TS, Takakura AC, Colombari E, Guyenet PG (2007a) Activation of 5-hydroxytryptamine type 3 receptor-expressing C-fiber vagal afferents inhibits retrotrapezoid nucleus chemoreceptors in rats. J Neurophysiol 98:3627-3637. CrossRef Medline

Moreira TS, Takakura AC, Colombari E, West GH, Guyenet PG (2007b) Inhibitory input from slowly adapting lung stretch receptors to retrotrapezoid nucleus chemoreceptors. J Physiol 580:285-300. CrossRef Medline

Mulkey DK, Stornetta RL, Weston MC, Simmons JR, Parker A, Bayliss DA, Guyenet PG (2004) Respiratory control by ventral surface chemoreceptor neurons in rats. Nat Neurosci 7:1360-1369. CrossRef Medline

Mulkey DK, Rosin DL, West G, Takakura AC, Moreira TS, Bayliss DA, Guyenet PG (2007) Serotonergic neurons activate chemosensitive retrotrapezoid nucleus neurons by a $\mathrm{pH}$-independent mechanism. J Neurosci 27: 14128-14138. CrossRef Medline

Nattie E (2000) Multiple sites for central chemoreception: their role in response sensitivity and in sleep and wakefulness. Respir Physiol 122:223235. CrossRef Medline

Nattie E (2011) Julius H. Comroe, Jr., Distinguished lecture: central chemoreception: then .... and now. J Appl Physiol 110:1-8. CrossRef Medline

Nattie EE, Li A (2002) Substance P-saporin lesions of neurons with NK1 receptors in one chemosensitive site in rats decreases ventilation and chemosensitivity. J Physiol 544:603-616. CrossRef Medline

Nawaratne V, Leach K, Suratman N, Loiacono RE, Felder CC, Armbruster BN, Roth BL, Sexton PM, Christopoulos A (2008) New insights into the function of M4 muscarinic acetylcholine receptors gained using a novel allosteric modulator and a DREADD (Designer Receptor Exclusively Activated by a Designer Drug). Mol Pharmacol 74:1119-1131. CrossRef Medline

Núñez-Abades PA, Morillo AM, Pásaro R (1993) Brainstem connections of the rat ventral respiratory subgroups: afferent projections. J Auton Nerv Syst 42:99-118. CrossRef Medline

Oku Y, Masumiya H, Okada Y (2007) Postnatal developmental changes in activation profiles of the respiratory neuronal network in the rat ventral medulla. J Physiol 585:175-186. CrossRef Medline

Onimaru H, Homma I (2003) A novel functional neuron group for respira- 
tory rhythm generation in the ventral medulla. J Neurosci 23:1478-1486. Medline

Onimaru H, Ikeda K, Kawakami K (2008) $\mathrm{CO}_{2}$-sensitive preinspiratory neurons of the parafacial respiratory group express Phox $2 \mathrm{~b}$ in the neonatal rat. J Neurosci 28:12845-12850. CrossRef Medline

Pagliardini S, Janczewski WA, Tan W, Dickson CT, Deisseroth K, Feldman JL (2011) Active expiration induced by excitation of ventral medulla in adult anesthetized rats. J Neurosci 31:2895-2905. CrossRef Medline

Pei Y, Rogan SC, Yan F, Roth BL (2008) Engineered GPCRs as tools to modulate signal transduction. Physiology 23:313-321. CrossRef Medline

Portillo F, Núñez-Abades A (1992) Distribution of bulbospinal neurones supplying bilateral innervation to the phrenic nucleus in the rat. Brain Res 583:349-355. CrossRef Medline

Putnam RW, Conrad SC, Gdovin MJ, Erlichman JS, Leiter JC (2005) Neonatal maturation of the hypercapnic ventilatory response and central neural $\mathrm{CO}_{2}$ chemosensitivity. Respir Physiol Neurobiol 149:165-179. CrossRef Medline

Ray RS, Corcoran AE, Brust RD, Kim JC, Richerson GB, Nattie E, Dymecki SM (2011) Impaired respiratory and body temperature control upon acute serotonergic neuron inhibition. Science 333:637-642. CrossRef Medline

Rosin DL, Chang DA, Guyenet PG (2006) Afferent and efferent connections of the rat retrotrapezoid nucleus. J Comp Neurol 499:64-89. CrossRef Medline

Sherrey JH, Pollard MJ, Megirian D (1988) Proprioceptive, chemoreceptive and sleep state modulation of expiratory muscle activity in the rat. Exp Neurol 101:50-62. CrossRef Medline

Smith JC, Morrison DE, Ellenberger HH, Otto MR, Feldman JL (1989) Brainstem projections to the major respiratory neuron populations in the medulla of the cat. J Comp Neurol 281:69-96. CrossRef Medline

Smith JC, Ellenberger HH, Ballanyi K, Richter DW, Feldman JL (1991) PreBötzinger Complex: a brainstem region that may generate respiratory rhythm in mammals. Science 254:726-729. CrossRef Medline

Stornetta RL, Guyenet PG (1999) Distribution of glutamic acid decarboxylase mRNA-containing neurons in rat medulla projecting to thoracic spinal cord in relation to monoaminergic brainstem neurons. J Comp Neurol 407:367-380. CrossRef Medline
Stornetta RL, Moreira TS, Takakura AC, Kang BJ, Chang DA, West GH, Brunet JF, Mulkey DK, Bayliss DA, Guyenet PG (2006) Expression of Phox $2 \mathrm{~b}$ by brainstem neurons involved in chemosensory integration in the adult rat. J Neurosci 26:10305-10314. CrossRef Medline

Stornetta RL, Spirovski D, Moreira TS, Takakura AC, West GH, Gwilt JM, Pilowsky PM, Guyenet PG (2009) Galanin is a selective marker of the retrotrapezoid nucleus in rats. J Comp Neurol 512:373-383. CrossRef Medline

Stunden CE, Filosa JA, Garcia AJ, Dean JB, Putnam RW (2001) Development of in vivo ventilatory and single chemosensitive neuron response to hypercapnia in rats. Respir Physiol 127:135-155. CrossRef Medline

Takakura AC, Barna BF, Cruz JC, Colombari E, Moreira TS (2014) Phox2bexpressing retrotrapezoid neurons and the integration of central and peripheral chemosensory control of breathing in conscious rats. Exp Physiol 99:571-585. CrossRef Medline

Tan EM, Yamaguchi Y, Horwitz GD, Gosgnach S, Lein ES, Goulding M, Albright TD, Callaway EM (2006) Selective and quickly reversible inactivation of mammalian neurons in vivo using the Drosophila allatostatin receptor. Neuron 51:157-170. CrossRef Medline

Tan W, Janczewski WA, Yang P, Shao XM, Callaway EM, Feldman JL (2008) Silencing preBötzinger complex somatostatin-expressing neurons induces persistent apnea in awake rat. Nat Neurosci 11:538-540. CrossRef Medline

Tan W, Pagliardini S, Yang P, Janczewski WA, Feldman JL (2010) Projections of preBötzinger Complex neurons in adult rats. J Comp Neurol 518:1862-1878. CrossRef Medline

Tanaka I, Ezure K, Kondo M (2003) Distribution of glycine transporter 2 mRNA-containing neurons in relation to glutamic acid decarboxylase mRNA-containing neurons in rat medulla. Neurosci Res 47:139-151. CrossRef Medline

Tupal S, Huang WH, Picardo MC, Ling GY, Del Negro CA, Zoghbi HY, Gray PA, Calabrese RL (2014) Atoh1-dependent rhombic lip neurons are required for temporal delay between independent respiratory oscillators in embryonic mice. eLife 3:e02265. CrossRef Medline

Yuste R (2008) Circuit neuroscience: the road ahead. Front Neurosci 2:6-9. CrossRef Medline 